\title{
Distributed Battery Energy Storage Co-Operation for Renewable Energy Sources Integration
}

\author{
Hussein M. Abdeltawab ${ }^{1, *(1)}$ and Yasser A. I. Mohamed ${ }^{2}$ \\ 1 Department of Electrical and Computer Engineering Technology, School of Engineering, Pennsylvania State \\ University, Behrend College, Erie, PA 16563, USA \\ 2 Department of Electrical and Computer Engineering, University of Alberta, \\ Edmonton, AB T6G 2V4, Canada; yasser2@ualberta.ca \\ * Correspondence: hza5222@psu.edu
}

Received: 20 September 2020; Accepted: 17 October 2020; Published: 21 October 2020

check for updates

\begin{abstract}
This paper presents a multiagent system (MAS) day-ahead co-operation framework between renewable energy resources (RESs) and Battery Energy Storage Systems (BESSs) owned by different stakeholders. BESSs offer their storage services to RESs by shifting RES power to sell it during profitable peak-hours (aka; time-shifting). The MAS framework consists of three phases. Phase-one is a pre-auction phase that defines the maximum charging and discharging BESS power limits. These limits guarantee a reliable distribution system operation without violating the buses' voltage limits or the ampacity of the branches. Phase-two is an auctioning phase between the BESS-agents and the RES-agents. Each agent has a different owner with a specific profit agenda and risk levels. The agent tries to maximize the profit potential of the owner. The agents use historical trade data and expected weather conditions to maximize profitability. Phase-three is called the post-auctioning phase, in which the agreement between the BESS- and RES-agents is finalized, and the agents are ready for another 3-phases trade. Case studies compare different auctioning strategies and prove the effectiveness of the proposed MAS system.
\end{abstract}

Keywords: energy trading; multiagent system (MAS); energy management; energy storage systems; smart grid; time-shifting

\section{Introduction}

In the future, power distribution systems will contain many renewable energy resources (RESs) and Battery Energy Storage Systems (BESSs) with different owners. Co-operation between the RESs and BESSs is possible by power shifting, which maximizes all owners' profit while conveying many benefits for the utility. This co-operation scheme needs to work under a distributed system for the following reasons:

$1 \quad$ BESSs and RESs are owned by different stakeholders who have a unique trading strategy and risk level.

2 Each system has a different model, operational costs, and technical constraints.

3 With a large number of participants, a centralized energy management solution might not be feasible.

Motivated by the reasons above, this work proposes a multiagent system (MAS) trading framework for co-operation between RESs and BESSs. The MAS framework is performed under the supervision of the distributed network operator (DNO). The DNO guarantees no power flow violations without interfering in the economic part of the MAS trades. 
In literature, MAS has many applications in the area of distributed control [1]. An MAS has been adopted in [2] for droop control of multi BESS to control active and reactive power. MAS has been adopted for power balance in [3] using the particle swarm algorithm. An MAS investigated the current chattering problem of distributed BESS in a DC microgrid in [4]. The idea of a community energy storage system (CESS) is discussed in [5], where different microgrids can achieve power balance via trading with the CESS plus using other methods like demand response. The work in [6] has proposed an MAS power exchange and trading between different microgrids. State of charge (SOC) balance of BESSs in an AC microgrid was solved by an MAS frequency scheduling control [7]. An MAS is proposed in islanded microgrid [8] for reactive power sharing between ESSs via two levels framework. An internal market for islanded microgrids' trading has been proposed in [9] using MAS. Wind power intermittency may affect the frequency stability at high penetration; the authors of [10] proposed an MAS for BESSs to solve this problem while maximizing the BESS profit. MAS has been proposed for microgrid restoration in [11] using mobile energy storage and distributed generators. Power restoration has also been proposed in [12] using a consensus algorithm to maximize system reliability and define the optimal power restoration plan. An MAS has been used to improve the transient stability of the power system, as in [9], ESSs have been controlled to accommodate angle and frequency disturbance. In [10], the MAS successfully implemented EV collaboration to minimize energy cost while overloading the transformer, using reinforcement learning (RL). The authors of [13] represented an MAS framework of ESS participation in the market using RL. Recently, MAS was adopted in the electricity market negotiations. In [14], the authors propose a trading framework between virtual power plants (VPPs) using MAS. The negotiations consist of three levels. First, the internal negotiations are between the load and generation agents of the same VPP. Second, the negotiations are between VPP agents that sell any energy surplus or buy any shortage. Finally, the VPPs with power imbalance trade with the grid. The authors used the Multiagent Scheme of Competitive Electricity Markets (MASCEM) software to validate the results. In the electricity market, intelligent auctioning MAS has been investigated by the Electric Power Research Institute [15]. Their MAS software [15] Simulator for Electric Power Industry Agents (SEPIA) can simulate power market scenarios between intelligent agents with different auctioning techniques.

In [16], each agent aims to maximize his profit and minimize the fuel cost using IPSO optimization. A risk management- auction agent is designed to adjust the risk level in bid/ask prices. Another auction strategy between grid-connected microgrids is proposed in [17]. The authors of [17] propose a demand response agent (DRA) that implements peak shaving by trading between the microgrids agents. The DRA initiates an auction scheme between different microgrids. It adopts a continuous double auction (CDA) protocol to maximize the generating microgrids' profit. The storage cluster agent regulates any power imbalance. Another auction algorithm, like naïve auction, is discussed in [18]. This auction aims at maximizing the profit for all parties fairly by applying a constraint on the difference between the maximum profit and any other profit. A naïve algorithm is proposed in [19] with a two-level MAS structure. The first level is the field level, which consists of the load and the generator agents who aim to fuel cost reduction. These agents bid in the market by sending their bid/ask offers to a higher level (market level). A naïve auction algorithm is applied to trade with the agents or with the grid at the market level. Unfortunately, the techniques above do not consider the prediction error of RESs or the market price uncertainty during agents' negotiations. The power flow constraints (voltage limits, power losses, lines ampacity, and reversal power flow) are not addressed in the previous works during the auctioning strategy.

Recently, the authors of [20] proposed an MAS trading scheme between smart homes and the utility, taking into account the RES and market uncertainty. Using data-based random models, the market and RES data are predicted from former trades and previous days' measurements. The smart home has three agents to switch between three modes (the load agent who exports power from the grid to the house; the storage agent who stores energy in the battery; and the sell agent who imports power from the house to the grid). These agents compromise between the house comfort level and the potential 
profit from the energy market to decide the appropriate trading mode. The parameter uncertainty is considered by a two levels MAS scheme in [21]. The higher level is the day-ahead level. In this level, the RES, load, and market predictions are assumed to be exact. These predictions are utilized in a profit maximization dispatch, where the predictions are used for demand-side management (DSM) for load shifting using a genetic algorithm (GA). The second level is for real-time control with a five minute sampling time. The second level measures the short term load, RES, and market forecasts, and it corrects the setpoints assigned by the day-ahead level. However, power flow constraints are not considered in [21]. The previous works do not consider the battery expended life cost and the effect of the daily number of batteries' charging cycles. The authors of [22,23] designed an event-driven MAS system for a grid-connected microgrid. The microgrid combines a battery with a diesel engine. The authors consider the expended life cost and the round trip efficiency; however, the real contribution of MAS flexibility cannot appear with such a small system, and the topology has not considered the RES uncertain generation. In DC microgrid, the authors of [24] proposed a secondary voltage controller using MAS. The proposed MAS regulates the voltage while balancing the SOC of different storages. The work in [25] proposed an ESS trading scheme in microgrids. Q-learning is used to develop the agent's learning strategy. The technique accounts for the power losses during the trading, but the RES was not represented by an agent. The authors of [26] proposed a two-level MAS framework for RES energy utilization. The technique maximizes the use of RES energy by storing it on the microgrid level using ESS and demand-side management. The second level shares the rest of the RES energy with other microgrids.

Motivated by the reasons above, this works proposes a comprehensive MAS trading scheme for BESSs and RESs to cooperate and bid in the energy market. This work has the following contributions to the research:

1 Considering the power flow model in the MAS framework.

2 Proposing the idea of the MAS trading packages; as each ESS-MAS has different packages of storage plans with varying prices. The price of any package depends on the storage depth of discharge (DOD) and the daily number of cycles (DNC).

3 Developing MAS agents with learning capabilities. The learning process takes into account the market status, MAS trade history, and the RES generation.

4 Proposing different auctioning strategies between the agents. The strategies represent the diverse risk levels and bargaining ways to give the agent variety of choices during trading.

This paper is arranged as follows: Section 2 briefly describes the system model, while Section 3 explains the different energy management modes of the agents. Section 4 proposes the trading strategies between the agents. To evaluate and validate the proposed algorithms, Section 5 presents a case study for the system on a typical 41-bus real distribution feeder. Finally, the conclusions are drawn in Section 5 .

\section{Problem Formulation}

This work proposes a co-operation between different BESSs and RESs scattered in a power distribution system for the time-shifting of the RES energy to be sold during peak-hours. The MAS agents are driven by the profit resulting from the energy price difference. The trading process needs to include the power flow model; otherwise, it may lead to serious power quality and reliability issues, such as over/under voltage, reverse power flow, branches overcurrent, etc. [27]. The DNO is represented by an agent to guarantee an acceptable power system quality and reliability. The proposed MAS has the following agents:

1 The ESS-agent: it targets maximizing the BESS owners' net profit. The ESS-agent accounts for the ESS storage cost [28] and the ESS expended life cost (depletion cost) [29] of the battery (which is a function of the DOD and the daily number of cycles (DNC). The agent applies the auctioning strategy and risk management levels when dealing with RES-agents. 
2 The RES-agent: this agent aims at maximizing the owner's profit either by trading directly with the grid as a price taker or by cooperating with other ESS-agents to make a higher profit from the daily energy price's difference. The RES-agent accounts for its expected energy prediction error as it represents a risk factor for his profit.

3 The grid agent: it represents the energy market. It contracts with any ESS-agent or buys energy from any RES directly as a price taker. It provides the expected market price to all agents.

4 The distributed network operator (DNO): it guarantees that all the trading deals will not violate the power system constraints.

\subsection{MAS Modes}

Different agents can work together through three operating modes: The Energy-Arbitrage Mode, The Price Taker Mode, and The Time Shifting Mode.

\subsubsection{Energy-Arbitrage Mode (EA)}

In this mode, the expected agent profit results from the daily energy price difference. The BESS day-ahead dispatch is defined by (1).

$$
\begin{gathered}
\max _{\mathrm{p}_{\mathrm{k}}^{s}}\left(p r o_{E A} A^{s}\right) \\
\text { s.t. }\left\{\begin{array}{c}
0 \leq c h_{k}^{s} \leq p r^{s}-p r^{s} \leq d c_{k}^{s} \leq 0 \\
p_{k}^{s}=c h_{k}^{s}+d c_{k}^{s} \\
d l_{k}^{s} \leq p_{k}^{s} \leq c l_{k}^{s} \\
N_{k+1}^{S}=N_{k}^{S}+\frac{\left(\eta c^{s} c h_{k}^{s}-\eta d^{s} d c_{k}^{s}\right)}{2 \overline{2}^{s}} 0 \leq N_{k}^{s} \leq \bar{N} \\
\operatorname{SOC}_{k+1}^{S}=S O C_{k}^{S}+\frac{\left(\eta c^{s} c h_{k}^{S}+\eta d^{s} d c_{k}^{s}\right)}{\bar{E}^{s}} \underline{S O C} \leq S O C_{k}^{s} \leq 1
\end{array}\right.
\end{gathered}
$$

The energy arbitrage profit $\left(p o_{E A}^{s}\right)$ for a storage unit s results from the income of selling the power for a higher market price $M p_{k}$ while charging power $d c_{k}^{s}$ during cheap hours as in (7), the storage cost includes the fixed storage cost $\left(F S C^{s}\right)$ plus a variable daily expended life $\operatorname{cost}\left(E L C^{s}\right)$. The $F S C^{s}$ accounts for the power conversion cost, the balance of operation, the replacement cost, and the maintenance cost. The $F S C^{s}$ is calculated per charged unit of power $(\$ / \mathrm{kW})$. The $E L C^{s}$ depends on the daily number of cycles $\left(N_{k=24}^{s}\right)$ and the minumum state of charge $\underline{S O C^{s}}$ [30] as shown in (8) where $S U C^{s}, a^{s}$, and $b^{s}$ are the storage (\$), and constants depends on the battery type [30].

$$
\begin{gathered}
\operatorname{pro}_{E A}^{s}=\left(\sum_{k=1}^{24} M p_{k}\left(c h_{k}^{s}-d c_{k}^{s}\right)-F S C^{s} c h_{k}^{s}-E L C^{s}\right. \\
E L C^{s}=S U C^{s} \frac{\overline{N^{s}}}{a^{s}\left(1-\underline{S O C^{s}}\right)+b^{s}}
\end{gathered}
$$

The optimization constraints (2)-(6) represent the BESS model and operational constraints. First, the charge and discharge power are limited in (2). The discharge power is negative while the charge power is positive; both powers are limited by the BESS rated power. The total BESS power is the sum of the charge and the discharge power (3). The BESS power is limited in (4) by power flow limits $d l_{k^{\prime}}^{s}$, and $c l_{k}^{s}$ which are imposed by the DNO. These limits are explained in detail in the pre-auction phase. The BESS daily number of charging cycles $\left(N_{k}^{S}\right)$ is calculated and limited in (5). If by the end of the day $(\mathrm{k}=24)$, the BESS has a sum of charged power $c h_{k}^{s}$ and discharged power $d c_{k^{\prime}}^{s}$, both equal to the rated BESS energy $\bar{E}^{s}$, then the number of cycles is incremented by one. The state of charge is calculated in (6). Both the charging and discharging efficiencies $\eta c^{s}, \eta d^{s}$ are considered. 
Each ESS-agent offers a package of storage plans (PKG) as in (9); each plan is defined by a maximum DNC and a maximum DOD $(\overline{D O D}=1-\underline{S O C}, \bar{N})$, as a result each storage plan has a different cost and profit. The best plan of these $\mathrm{z}$ plans is the one that achieves the maximum profit, as expressed in (10).

$$
\begin{gathered}
P K G^{s}=\left\{s p_{1}^{s}\left(\overline{D O D_{1}}, \bar{N}_{1}\right), \ldots, s p_{z}^{s}\left(\overline{D O D_{z}}, \overline{N_{z}}\right)\right\} \\
s p_{\text {best }}^{s}=\arg _{s p}\left(\max \left(\operatorname{pro}_{E A}^{s}\right)\right)
\end{gathered}
$$

It is worth mentioning that the market price for the day-ahead is uncertain. The profit is expressed by uncertain value within an interval or range. The profit range depends on the market price range, with a minimum, maximum, and expected profit values as in (11) and (12).

$$
\begin{gathered}
p r O_{E A}^{s} \in\left[\underline{\operatorname{pro}_{E A}^{s}}, \overline{p r O_{E A}^{s}}\right], E\left(p r o_{E A}^{s}\right)=P R O_{E A}^{s} \\
P R O_{E A}^{s}=\arg _{P R O}\left(\left(\operatorname{problem}(1) \mid M p_{k}=E\left(M p_{k}\right)\right)\right)
\end{gathered}
$$

\subsubsection{Price Taker Mode (PT)}

In this mode, the RES-agent sells its energy directly to the grid agent and is treated as a price taker. The RES-agent obligates to keep the upper limit of the generated power and uses necessary curtailment techniques to cut off any off-limit generated power or power rate. The resulting profit in the PT mode is calculated in (13).

$$
\operatorname{pro}_{P T}^{r}=\sum_{k=1}^{24}\left(M p_{k}-C^{r}\right) p_{k}^{r}
$$

where $\operatorname{pro}_{p t}^{r} \mathrm{C}^{r}, p_{k}^{r}$ are the agent $r$ profit in from the mode $p t$, the RES $r$ Levelized generation cost in $\$ / \mathrm{kWh}$, and the RES $r$ expected generated power at the time $k$. Without the loss of generality, the sampling time is assumed to be $1 \mathrm{~h}$, so the power $(\mathrm{kW})$ value equals the energy $(\mathrm{kWh})$. Both the RES power and the market price are uncertain. The profit is an uncertain variable expressed by an interval and expected value as in (14), (15).

$$
\begin{gathered}
\operatorname{pro}_{P T}^{r} \in\left[\underline{\text { pro }_{P T}^{r}} \overline{, p r o_{P T}^{r}}\right], E\left(p r o_{P T}^{r}\right)=P R O_{P T}^{r} \\
P R O_{P T}^{r}=\arg _{P R O}\left(\text { Equation }(13) \mid\left(M p_{k}, p_{k}^{r}\right)=E\left(M p_{k}, p_{k}^{r}\right)\right)
\end{gathered}
$$

In some markets, such as the Spanish energy market, there is a penalty for violating the contracted energy limits [31]. In such a case, this penalty can be added to the problem (13), as explained in [31]. The maximum and minimum profits $\mathrm{pro}_{P T}^{r}, \overline{{ }^{2} r_{P T}^{r}}$ will be used by the RES-agent to define the risk management strategy. The maximum profit $\overline{\left(\text { pro }_{p t}^{r}\right)}$ occurs at maximum RES generation when energy market price is maximum, and vice versa for the minimum expected profit $\left(\mathrm{pro}_{P T}^{r}\right)$.

\subsubsection{Time Shifting Mode (TS)}

In this mode, there is a co-operation deal between the RES and ESS-agents. The RES stores part of its energy in a BESS during high generation, off-peak hours [32]. Later, The BESS sells this energy back to the grid when the price is higher. As a result, the BESS and RES act as a single hybrid system. The profit of the TS mode is calculated in (16).

$$
p r o_{T S}^{s r}=\sum_{k=1}^{24} M p_{k} p_{k}^{s r}-\left(F S C^{s} c h_{k}^{s}+E L C^{s}+C^{r} p_{k}^{r}\right)
$$


where $p_{k}^{s r}$ is the total power imported or exported by the hybrid system as in (18). The profit is calculated similarly to the problem (1) as given in (17).

$$
\begin{gathered}
\max \left(\operatorname{pro}_{T S}^{s r}\right) \\
\text { s.t. }\left\{\begin{array}{c}
c p_{k}^{s r}=p_{k}^{r}-p_{k}^{s} \\
p_{k}^{s} \leq p_{k}^{r} \\
(2)-(6)
\end{array}\right.
\end{gathered}
$$

The constraint (19) ensures that the BESS only buys the RES energy without buying more energy from the grid. The maximum profit plan is chosen by comparing the different storage plans from (9), (10). The profit range is calculated as an interval, including both the RES and market price uncertainty. The expected TS mode profit is calculated in (21), (22)

$$
\begin{gathered}
\operatorname{pro}_{T S}^{s r} \in\left[\underline{p r o}_{T S}^{s r}, \overline{p r O_{T S}^{s r}}\right], E\left(p r o_{T S}^{s r}\right)=P R O_{T S}^{s r} \\
P R O_{T S}^{s r}=\arg _{P R O}\left(\operatorname{problem}(17) \mid\left(M p_{k}, p_{k}^{r}\right)=E\left(M p_{k}, p_{k}^{r}\right)\right)
\end{gathered}
$$

Since RES and BESS are owned by different stakeholders, the profit $P R O_{T S}^{s r}$ is shared according to auctioning negotiation between both RES- and ESS-agents, as explained in Section 3.

\section{Proposed MAS Trading Strategy}

Energy markets are either day-ahead or intra-day markets where (DERs) are rescheduled to fit with price changes and the RES intermittent generation. For day-ahead markets, the negotiations period ends when all the deals are finalized between the different agents before midnight. The negotiation period is proposed in three phases (pre-auction, auction, post-auction). First, in the pre-auction phase, the expected day-ahead market price is announced. At the same time, the RES day-ahead predictions are ready. The DNO calculates the power operating limits for each BESS $\left(d l_{k^{\prime}}^{s} c l_{k}^{s}\right)$. Second, during the auction phase, each BESS- and RES-agent decides the best operation mode (EA, PT, or TS). Finally, the post-auction is when all the deals are finalized and approved by the DNO; then, the operation period starts with the day's start. More details are mentioned in [16].

\subsection{Phase-A (The Pre-Auction Phase)}

In this phase, the DNO-agent assigns the charging and discharge power limits $\left(d l_{k^{\prime}}^{s} l_{k}^{s}\right)$ for all ESSs. These limits define the safe charge and discharge powers for DSs without technical constraints violation (voltage limits, cables ampacity, and reversal power flow). The limits are generated by solving the optimal power flow problems (23).

$$
\begin{gathered}
\max _{p_{k^{\prime}}^{s} q_{k}^{s}}\left(\sum_{s} \sum_{k} \frac{p_{k}^{s}}{p r^{s}}\right) \\
p_{k}^{i}=\sum_{j=1}^{n_{b}}\left|v_{k}^{i}\right|\left|v_{k}^{j}\right|\left(G^{i j} \cos \left(\delta_{k}^{i j}\right)\right)+\left(B^{i j} \sin \left(\delta_{k}^{i j}\right)\right) \\
q_{k}^{i}=\sum_{j=1}^{n_{b}}\left|v_{k}^{i}\right|\left|v_{k}^{j}\right|\left(G^{i j} \sin \left(\delta_{k}^{i j}\right)\right)-\left(B^{i j} \cos \left(\delta_{k}^{i j}\right)\right) \\
p_{k}^{i}=p_{k}^{l i}+p_{k}^{s i}+p_{k}^{r i}+p_{k}^{g i} \\
q_{k}^{i}=q_{k}^{l i}+q_{k}^{s i}+q_{k}^{r i}+q_{k}^{g i}
\end{gathered}
$$




$$
\begin{gathered}
I_{k}^{t}=\left|v_{k}^{i}-v_{k}^{j}\right|\left|G^{i j}+j B^{i j}\right|, \forall t: i \rightarrow j \\
p \operatorname{loss}_{k}=\sum_{t=1}^{n_{T}} I_{k}^{t 2} Z^{t} \\
v_{\min } \leq v_{k}^{i} \leq v_{\max } \\
I_{k}^{t} \leq \overline{I^{t}} \\
p_{\text {loss }} \leq \bar{p}_{\text {loss }} \\
\underline{p}_{\text {grid }} \leq p_{k}^{l=g \text { grid }} \leq \bar{p}_{\text {grid }} \\
p_{k}^{s 2}+q_{k}^{s 2} \leq p r^{s 2} \\
0 \leq p_{k}^{s} \leq p r^{s}
\end{gathered}
$$

Problem (23) aims at maximizing the BESSs power participation in the system for day-ahead. For a fair maximization of all BESS units, the sum of the per-unit power of all BESSs is maximized. The AC-power flow model is presented in (24), (25) for each bus $i$ active and reactive power $p_{k^{\prime}}^{i} q_{k^{\prime}}^{i}$ while each bus power balance is expressed in (26), (27), where the bus power is the sum of the load power $p_{k}^{l i}$, the storage power $p_{k}^{s i}$, the RES power $p_{k}^{r i}$, and the DER power $p_{k}^{g i}$ at the bus $i$. For each branch $t$, the current magnitude is calculated in (28). The total power losses ploss $_{k}$ is the sum of all branchs' losses as given in (29). The power flow constraints are stated in (30)-(31) for the voltage, cables ampacity, power losses, and the grid power. Finally, the apparent power limits for each BESS are defined by (34), (35). Problem (23) is a nonconvex problem due to the power flow voltage constraints. Problem (23) is linearized by the power-voltage flow Jacobian. The decision variables are the maximum BESS active and reactive power $p_{k}^{s}, q_{k}^{s}$. Resolving problem (23) as a minimization problem results in the maximum BESS discharge power (since discharge power has a negative sign). Finally, the BESS limits (charging and discharging maximum powers) are expressed as in (36) and (37).

$$
\begin{gathered}
c l_{k}^{s}=\arg _{p_{k}^{s}} \max (23) s t .(24)-(35) \\
d l_{k}^{s}=\arg _{p_{k}^{s}} \min (23) \text { st. (24) }-(34),-p r^{s} \leq p_{k}^{s} \leq 0
\end{gathered}
$$

The pre-auction phase shows that the proposed MAS framework is not entirely decentralized because all the BESS-agents need to communicate with the DNO to define the permissible charging and discharging limits $c l_{k^{\prime}}^{s} d l_{k}^{s}$ before performing any trade.

\subsection{Phase-B (The Auction Phase)}

After the ESS-agent knows the power limits $\left(c l_{k^{\prime}}^{s} d l_{k}^{s}\right)$, the agent starts negotiating with the RES-agents one by one. Each ESS-agent has a trading list of the RES-agents. The ESS-agent acts as a selling agent who offers the storage plans to different RES-agents. Most probably, the first RES trade in the list will have the highest power share. Such a trade will happen to shift the RES energy to be sold during the most profitable times. The ESS-agent decides its favorable RES-agents by a trading list, as explained in the next section.

\subsubsection{The Trading List}

The trading list shows the order of the RES-agents that a specific ESS-agent will conduct. The trading list may have different design criteria. First, the list can be designed according to RESs' distance to the ESS. This criterion will be called the (distance rank). In the distance rank, the ESS-agent always starts negotiations with his nearer RES neighbors first and proceed to the next closer RES. Although distance rank is convenient and easy to develop, it does not guarantee a maximum profit 
for the ESS-agent. This paper proposes a learning algorithm for the ESS-agent; an adaptive fuzzy expert is suggested to organize the trading list for the ESS-agent according to the most profitable trades. This rank is called (profitability rank).

Profitability rank is arranging the trading list for the RES-agents according to their trade history and their expected generation. Expected RES generated power is estimated from the weather conditions. A higher-rank RES-agent will have a high expected generation and probably share a high profit of the TS trade with the ESS-agent. Previous deals or (trade history) are a good indication for the profit share ratio between the RES- and ESS-agents.

In this work, a fuzzy expert uses the trade history and expected weather data as inputs to defines each RES rank as an output. For the first input, assume $L$ RES-agents in the trading list, each RES trade history is estimated by the average historical profit as in (38);

$$
t h_{i}=\frac{\sum_{j=1}^{D_{i}} \operatorname{pro}_{j}}{D_{i}} \forall i=[1, l]
$$

where $t h_{i}, \operatorname{pro}_{j}, D_{i}$ are the trade history of the RES I, the profit made from storing power unit $(\$ / \mathrm{kWh})$ at the historical trade $j$, and the total number of deals made with the RES.

The second input is the expected weather at each RES area. This information is fetched easily from public weather websites. The fuzzy expert uses these two inputs to predict the RES rank. The expert is designed as a Sugeno rule-based model as the rank is inferred according to the rules in Table 1.

Table 1. Fuzzy expert rules.

\begin{tabular}{|c|c|c|c|}
\hline $\begin{array}{ll}\text { e History } & \text { Weather } \\
\end{array}$ & $\operatorname{Bad}\left(B_{1}\right)$ & Moderate $\left(B_{2}\right)$ & Good $\left(B_{3}\right)$ \\
\hline Low revenue $\left(A_{1}\right)$ & Low1 & Low2 & Medium3 \\
\hline Medium revenue $\left(A_{2}\right)$ & Low3 & Medium2 & High2 \\
\hline High revenue $\left(A_{3}\right)$ & Medium1 & High1 & High3 \\
\hline
\end{tabular}

Each input has three Gaussian bell membership functions [33]. The normalized trade history is defined as $x$, and a normalized value y expresses the weather condition. $x$ and $y$ are between $[0,1]$, The RES rank $z$ is inferred by the expert as in (39).

$$
\begin{gathered}
x=\left\{A_{1}, A_{2}, A_{3}\right\} \quad y=\left\{B_{1}, B_{2}, B_{3}\right\} \\
\left\{\begin{array}{c}
x=A_{1}, y=B_{1} \Rightarrow z_{1}=a_{1} x+b_{1} y+c_{1} ; \text { rule }(1) \\
x=A_{2}, y=B_{2} \Rightarrow z_{2}=a_{2} x+b_{2} y+c_{2} ; \text { rule }(2) \\
x=A_{3}, y=B_{3} \Rightarrow z_{3}=a_{3} x+b_{3} y+c_{3} ; \text { rule }(3)
\end{array}\right. \\
z=\sum_{i=1}^{r} w_{i} z_{i} \quad w_{i}=\frac{\lambda_{i}}{\sum_{i=1}^{3} \lambda_{i}} \quad \lambda_{i}=\operatorname{poss}\left(x, A_{i}\right) \operatorname{poss}\left(y, B_{i}\right)
\end{gathered}
$$

Given the set of inputs $x$ and $y$, the fuzzy rules are defined in Table 1. According to the input values, each rule is activated by a certain weight $w$, and the output is a weighted sum of all rules output. The weight of a rule reflects the degree of its membership activation or firing; $\lambda$, which is the minimum possibility (poss) of the rule's membership activation [33]. The resulting surface for this expert is as in Figure 1. The proposed fuzzy model is an expert-based model. It has the advantage of transparency and excellent utilization of the experts' knowledge to formulate the rules. However, it lacks high accuracy and may face completeness and consistency issues [33]. 


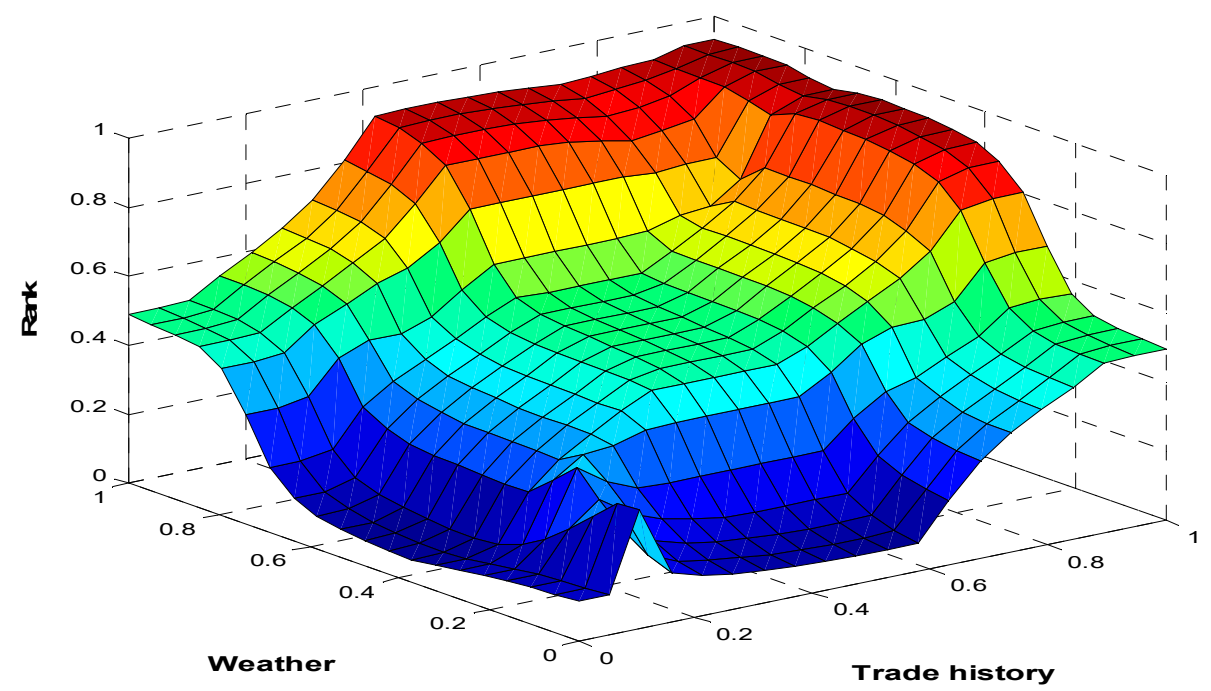

Figure 1. Fuzzy expert surface.

Another family of the fuzzy models is the data-driven fuzzy model. In this type, a data set of inputs and actual outputs is utilized to derive the fuzzy model (e.g., fuzzy clustering). Although data-driven models are more accurate than expert-models, it lacks transparency. A mix between expert-based and the data-driven models convey the advantages of both types. A useful tool for improving the expert-based fuzzy models' accuracy is by using Adaptive Neuro-Fuzzy Inference System (ANFIS) for expert learning. Expert learning is possible in ANFIS by tuning the membership function parameters to increase expert accuracy [34]. The back-propagation technique [31] is used to adjust the Gaussian bell memberships' parameters for our expert training. Finally, the resulting neural network is shown in Figure 2.

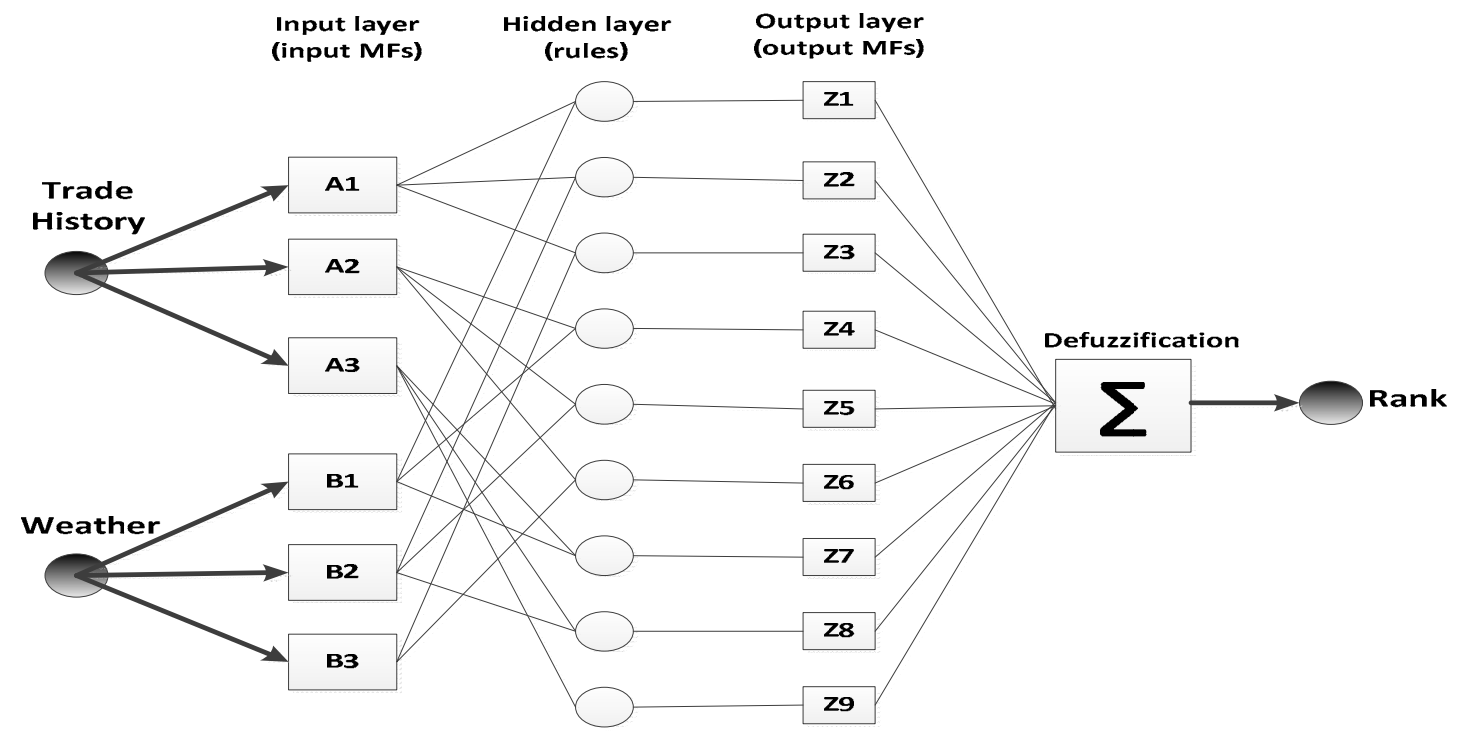

Figure 2. Fuzzy experts' structure after training, generated by the Adaptive Neuro-Fuzzy Inference System (ANFIS) toolbox, MATLAB [34].

This network has 35 nodes, and 45 membership parameters have been tuned. ANFIS uses a data set that contains inputs and the corresponding actual output for learning. $70 \%$ of the data set should be used for the model training, while $30 \%$ is used as test data to avoid model over-fitting [33]. It is always preferred to re-train the fuzzy expert periodically (e.g., every two weeks) to adapt to the market's environmental changes and with the RES-agents' behavior. 
Before the ESS-agent starts trading, the incoming day expected weather for all RES is given, and the trade history of each RES is also available. The fuzzy expert calculates each RES rank, and the trading list is generated accordingly. Figure 3 shows the structure of the trade list generation. One limitation of this technique is the time needed to collect the trading history data for each agent. There will be a learning curve to train each agent to decide its optimum trading list. The proposed framework has no plug and play feature; instead, the agents make better deals after conducting a certain number of trades with different agents and developing extensive trading data set.

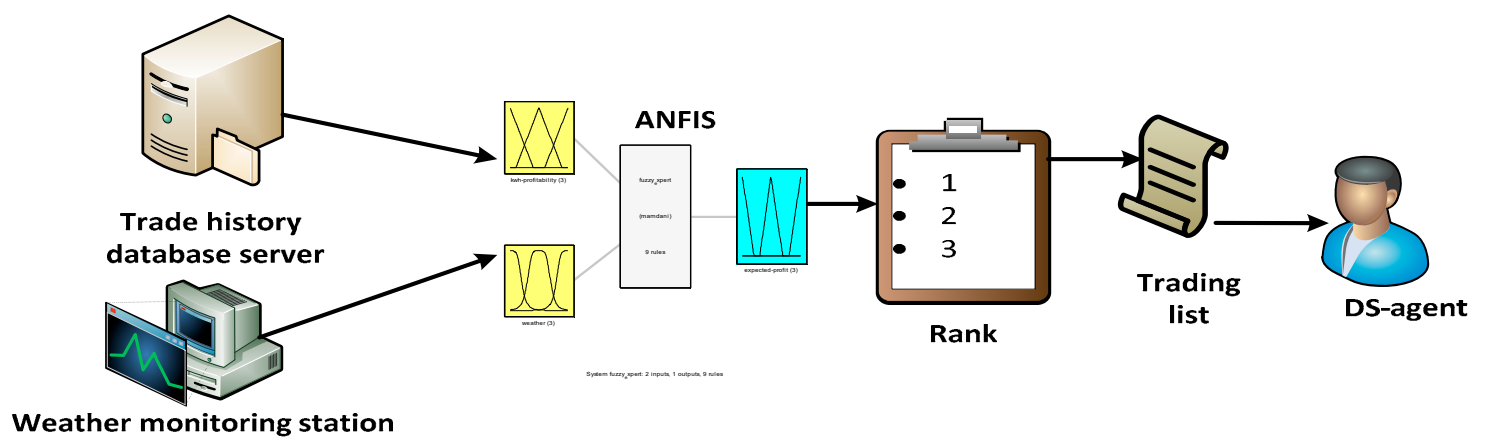

Figure 3. Trading list generation.

\subsubsection{The Offer}

First, the ESS-agent calculates his plans' ask prices. For trading in the time-shifting mode (TS-Mode), the profit must be higher than the energy arbitrage (EA-Mode). The ask price for storage plans $i$ is $c_{S i}$ is calculated as follows

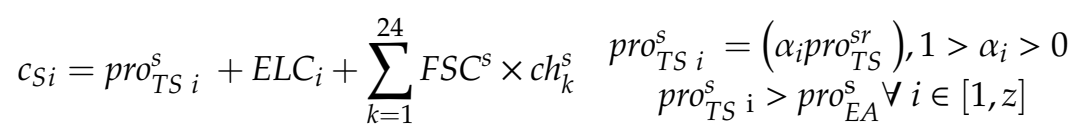

where $\mathrm{pro}_{T S i}^{S}, \alpha_{i}$ are the ESS profit share in $\$$ of the storage plan $i$ provided form a storage $s$ to an RES $r$, the ESS profit share of the total profit $p r o_{T S}^{s r}$ in case of collaboration with an RES in a TS-Mode. The ESS profit $\mathrm{pro}_{T S}^{s}{ }_{i}$ should be higher its EA-Mode profit, as explained in (40). Choosing the profit share $\alpha_{i}$ defines storage cost ask price RES. The higher $\alpha_{i}$ is, the greater the difference between the ask and bid prices will be, and the trade may fail. On the other hand, if it is deficient, the ESS-owner may waste potential higher profit. The parameter $\alpha_{i}$ can be adjusted by the ESS owner. The parameter $\alpha_{i}$ can be set using a fuzzy expert or from the trades' history. This issue will be investigated in future work.

\subsubsection{The Offer Evaluation}

As a response to the ESS-agent offer; each RES-agent calculates the profit in price taker mode $\left(\mathrm{pro}_{P T}^{r}\right)$. When an RES-agent receives an ESS-package of offers $\left(c_{D S i}\right)$, it picks the optimal storage plan $i$, and it calculates its profit $\left(p r o_{T S}^{r}=\left(p r o_{T S}^{s r}-p r o_{T S}^{s} i\right)\right)$. The RES-agent has three responses to the offer depending on the profit difference;

$$
\left\{\begin{array}{c}
\psi\left(\text { pro }_{T S}^{r}-\text { pro }_{P T}^{r}\right)<0 \rightarrow \text { Reject the offer } \\
\psi\left(\text { pro }_{T S}^{r}-\text { pro }_{P T}^{r}\right) \geq \beta \rightarrow \text { Accept the offer } \\
0<\psi\left(\text { pro }_{T S}^{r}-\text { pro }_{P T}^{r}\right)<\beta \rightarrow \text { counteroffer }
\end{array}\right.
$$

where $\beta$ is the desired RES profit share from trading with the ESS-agent. $\psi$ is statistic operator for the profit set $\left(\mathrm{pro}_{T S}^{r}-\operatorname{pro}_{P T}^{r}\right.$ ). It can be (min, max, mean), and the RES owner set it according to his risk level. If $\psi=\mathrm{min}$, then the RES-owner is cautious and wants to guarantee his profit even with the worst RES generation and lowest market price (low risk and low eagerness to trade). On the other hand, if $\psi=$ mean, then the RES-owner is moderate, and he trusts the market and RES generation predictions 
(medium risk level and moderate eagerness to trade). Finally, if $\psi=$ max, then the RES-owner expects higher than an expected generation and market profile (high-risk level and willingness to complete the trade). According to (41), the RES-agent has three possible responses:

- Reject: the first response means that the ESS-agent TS offer is not more profitable than the PT trade; so, it is rejected.

- Accept: the second means that the TS trade revenue is so high than the PT and the TS offer is accepted with no negotiations.

- Counter-offer: the third response means that the TS offer is profitable for the RES, but the profit is not that worthy. In such a case, the RES sends back a counter-offer for the storage (bid price $\widetilde{C_{S}}$ ) as in (42)

$$
\widetilde{c_{S}}=c_{S}-\left(\beta-\psi\left(\operatorname{pro}_{T S}^{r}-\operatorname{pro}_{P T}^{r}\right)\right)
$$

Many bargaining techniques can be adopted to share the profit between the RES and ESS-agents [15]. The agent negotiations behavior may take different forms according to market status and the risk level. Table 2 shows these various bargaining behaviors for both the seller (ESS-agent) and the buyer (RES).

Table 2. Different agents' bargaining techniques.

\begin{tabular}{ccccc}
\hline Strategy & \multicolumn{2}{c}{ ESS-Agent } & RES-Agent \\
\hline Anxious & \multicolumn{2}{c}{$C_{a}(k)=\frac{\widetilde{c_{S}}-c_{s}}{k_{f}} k+c_{D S}$} & $C_{b}(k)=\frac{c_{S}-\widetilde{c_{s}}}{k_{f}} k+\widetilde{c_{D S}}$ \\
\hline Cool-headed & $C_{a}(k)=a e^{b k}+c$ & $1>b>0$ & $C_{b}(k)=a e^{b k}+c$ & $1>b>0$ \\
& $a=\frac{\widetilde{c_{S}}-c_{s}}{e^{b k_{f}}-1}$ & $c=c_{D S}-a$ & $a=\frac{c_{S}-\widetilde{c_{s}}}{e^{b k_{f}}-1}$ & $c=\widetilde{c_{D S}}-a$ \\
\hline $\begin{array}{c}\text { Greedy } \\
\text { (frugal) }\end{array}$ & $C_{a}(k)=a e^{b k}+c$ & $b \geq 1$ & $C_{b}(k)=a e^{b k}+c$ & $b \geq 1$ \\
\hline & $a=\frac{\widetilde{c_{S}}-c_{s}}{e^{b k_{f}}-1}$ & $c=c_{D S}-a$ & $a=\frac{c_{S}-\widetilde{c_{s}}}{e^{b k_{f}}-1}$ & $c=\widetilde{c_{D S}}-a$ \\
\hline
\end{tabular}

During the total negotiation window $\left(k_{f}\right)$, each bargaining strategy emulates the agents' eagerness for different trade situations. For instance, the RES-agent will be anxious and eager for the deal's success if the market has high profitability potentials (high max to min prices ratio). On the contrary, the RES-agent can act greedy if the trade revenue is not appealing (RES high generation is aligned with the peak hour, or the market has a low max/min price). The trade is a success when the bid price $C_{b}$ reaches the ask price $C_{a}$. Figure 4 shows these different bargaining strategies and the resulting final price for all possible attitudes. In the negotiations, each agent retains the same approach during the negotiations period, regardless of the other agents' strategy. More intelligent negotiation techniques are proposed in [35]. The authors of [35] have developed a PSO-negotiator that uses a new factor that considers the eagerness of the other agent. However, our used technique is much simpler and needs less computational effort. 


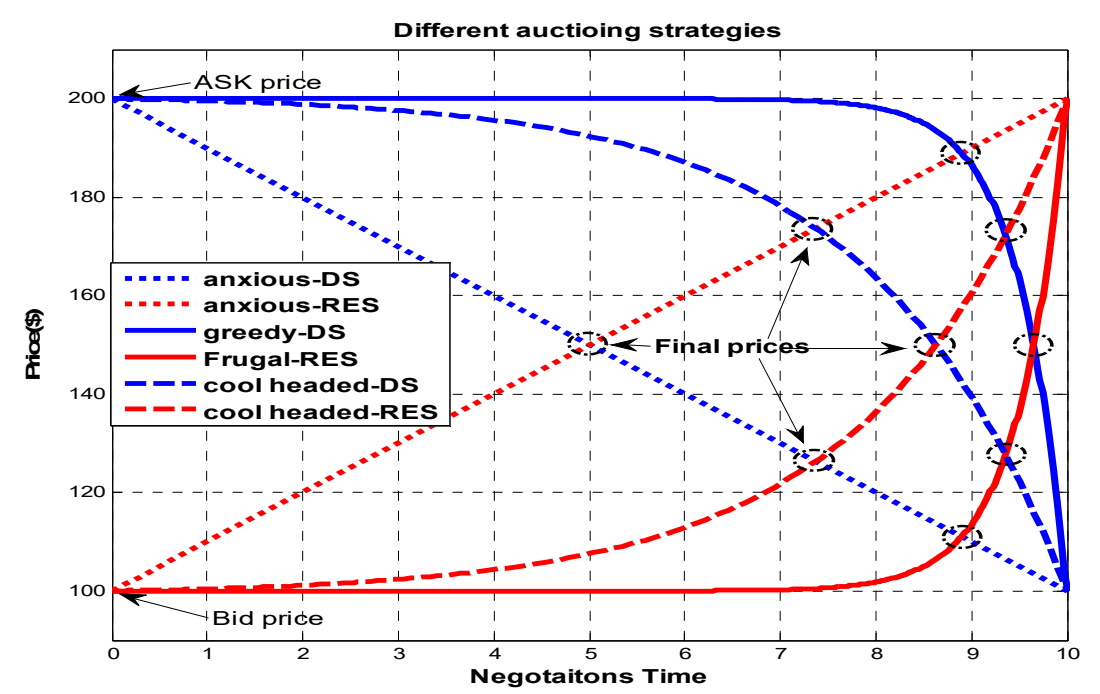

Figure 4. Different bargaining strategies between renewable energy resource (RES) and energy storage system (ESS) agents and the resulting final price.

\subsubsection{The Offer Response:}

If the negotiations have failed, the ESS-agent starts negotiating with the next agent in his trading list; otherwise, the agent continues the deal as in Phase-C (post-auction phase).

\subsection{Phase-C (The Post-Auction Phase)}

This phase is reached in case of successful trade between RES- and ESS-agents. Both agents must sign a digital contract for this deal with the DNO. The agreement contains the trade details (RES, BESS shares in profits, BESS charging, discharging power for the incoming day, etc.). After the DNO-agent rechecks that the BESS power is within power limit $\left(c l_{k^{\prime}}^{s} d l_{k}^{s}\right)$ margins, it approves the contract.

(1) After the contract approval, the ESS-agent updates the available power constraint and the initial state of charge (remaining capacity) in the battery to make another trade with another agent. The constraints update ensures that the BESS cannot discharge power for one RES while charging power for another RES and vice versa. It guarantees the power flow constraints and the state of charge limits for the new deal (d). On the other hand, The RES-agent updates its available power for trade by subtracting the contracted power with the BESS from its expected generation. The available RES power can be bought directly to the grid (PT-Mode) or contract with other BESS (TS-Mode) $c l_{k^{\prime}}^{s} d l_{k}^{s}$.

(2) After updating the power constraint, the ESS-agent starts trading with the next RES-agent in its trading list. The three phases are repeated until the list finishes, or the BESS capacity is fully occupied.

(3) After the first BESS-agent finishes negotiations, the DNO calls the next member in the BESS trading list, and so on till all ESSs finish trading.

(4) Finally, for all agents cooperate in a TS-Mode, all the bids are combined and traded in the global market. The profits of these trades are shared according to the auctioning results.

Figure 5 shows the interaction in the proposed MAS. MAS scheme has the advantage of being robust; if any ESS or RES is out of service, the scheme operation will not be affected. The MAS strategy has the merit of plug and play feature, as any RES- or ESS-agents can easily add the system. 


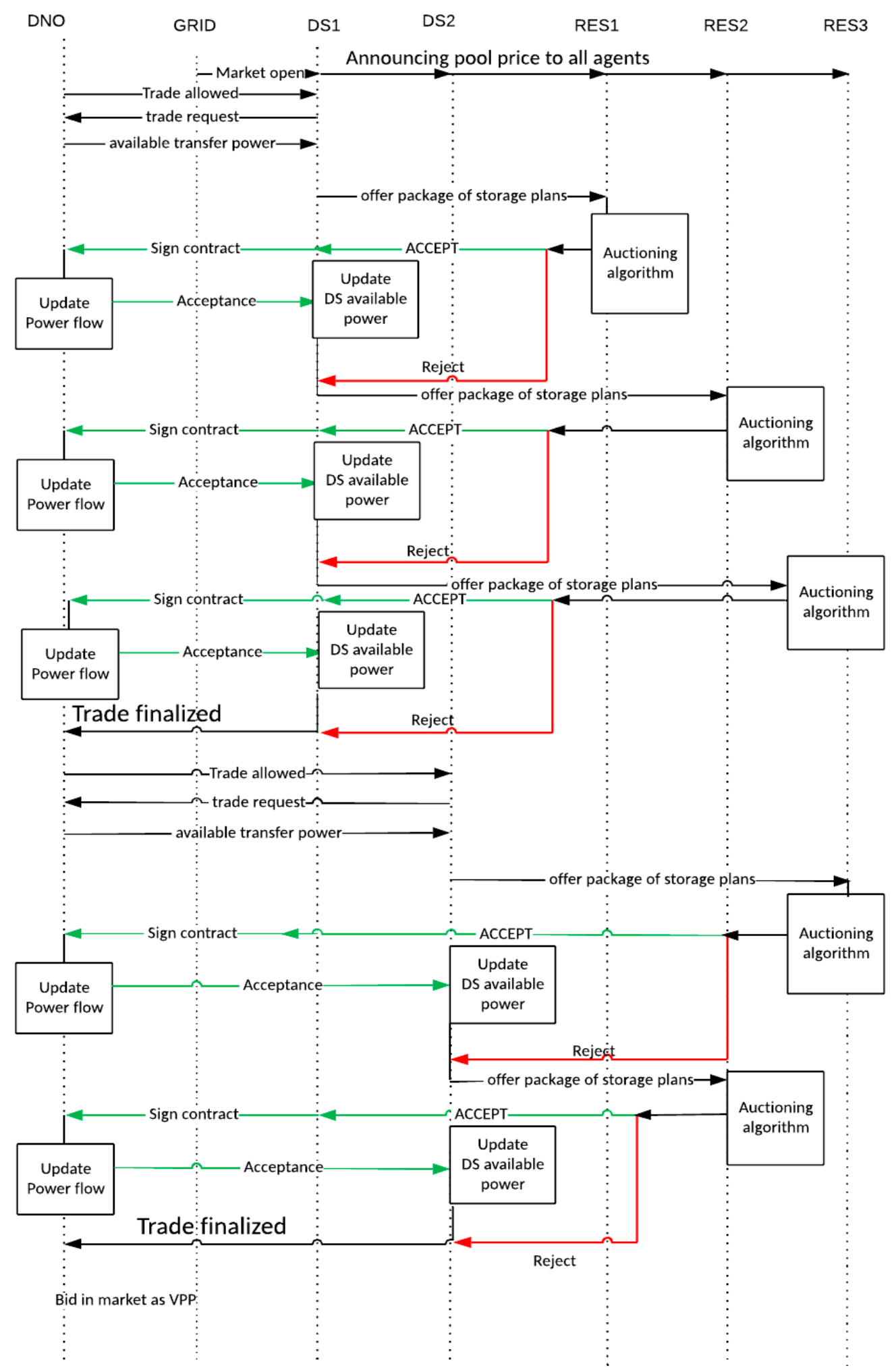

Figure 5. Interaction and communication between the agents.

\section{Case Study}

This study tested the proposed MAS on a real 41-bus radial feeder in Ontario [36]. The feeder rating is a $20 \mathrm{MVA}, 16 \mathrm{kV}$, as shown in Figure 6. It combines various loads ( $40 \%$ residential, $20 \%$ commercial, and $40 \%$ industrial) as per [37]. The system has five RESs with a gross power penetration 
of 30\% (6 MVA). Two ESS-agents are added to the network; battery storage (DS1) and a PEV parking lot (DS2). The total distributed storage represents (25\%) of the RES nominal power. The RES and storage allocation are adopted as in [36].

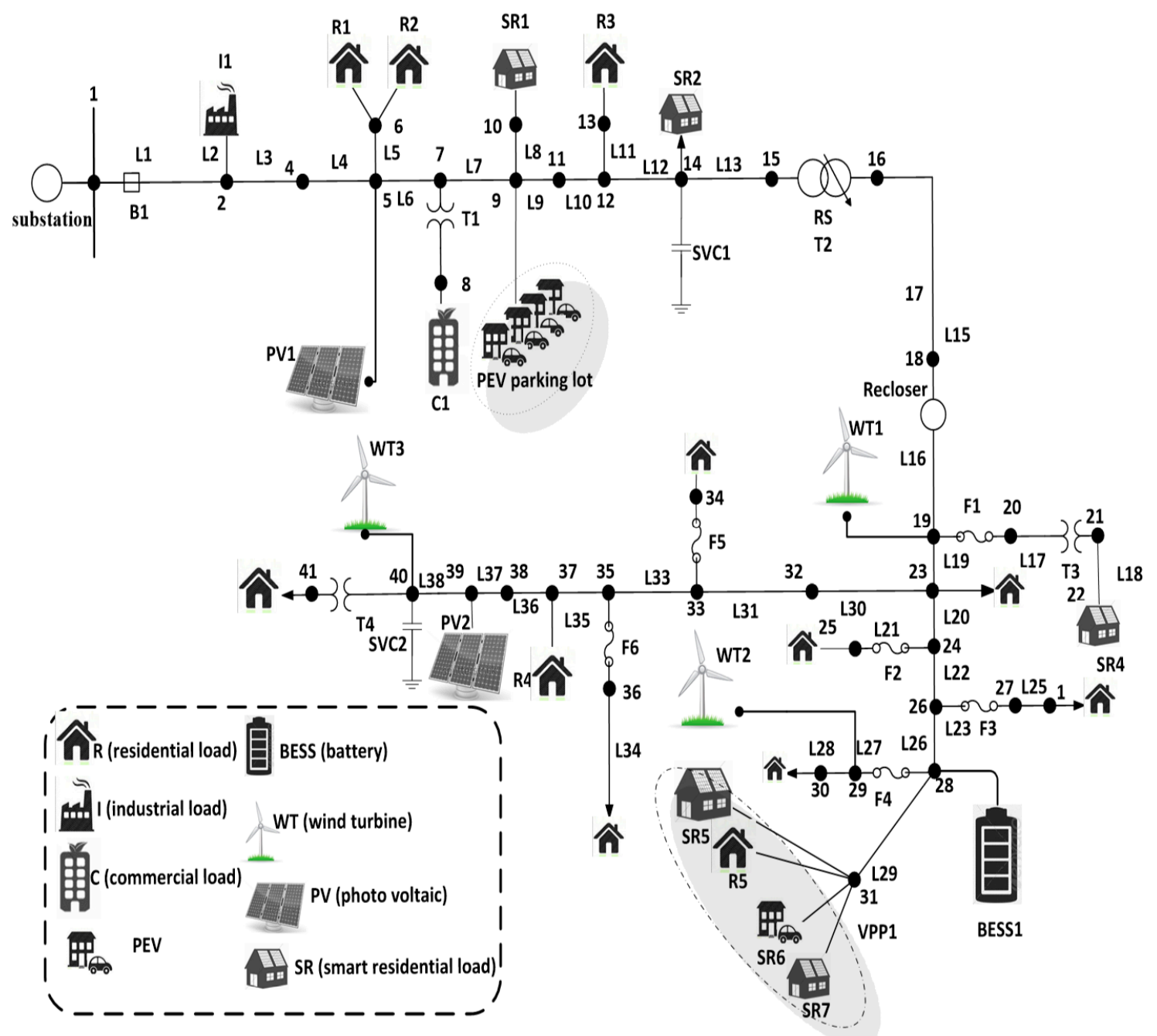

Figure 6. Distribution feeder diagram.

According to the DNO-agenda, the BESS starts trading first and then the parking lot, and they switch in the following day. In this simulation, real market price and the wind and PV powers are used from the Alberta electricity market [38]. The BESS costs are taken from [28]. The RES-agents are simulated with different risk strategies. WT1 represents a moderate agent, while WT2 acts as a greedy agent taking advantage of a location near DS1. On the other hand, WT3 is anxious to trade with any BESS as it has a far position from all DSs. Both PVs are eager to TS-Mode trade as the PV energy is only generated during daylight, which does not align with the market peak-hours. The bargaining attitude affects the trade history of each RES as it decides the profit share it splits with the BESS.

The trade history is related to previous deals' success. For instance, although PV1, PV2 are generous agents, they have a low rank in the PEV lot parking lot as it is allowed to charge energy only after mid-night, while the PV generation starts in the morning. On the other hand, all wind agents are assumed to have moderate weather except WT3, which has good weather. Figure 7 shows the RES power (min, expected, and max) and the corresponding PT profit range. Table 3 shows the different RES ranks. The distance rank is related to the physical distance from each BESS, while the proposed technique generates the profitability rank. Table 3 shows BESS storage plans and the DERs' different ratings. 
(a) Pool Price $(\$ / k W h)$

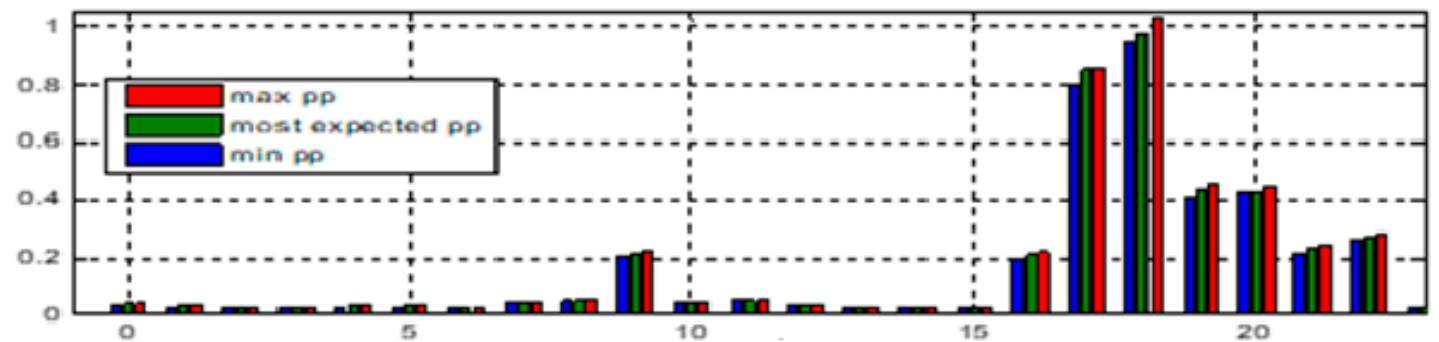

(b) RES Power (kW)

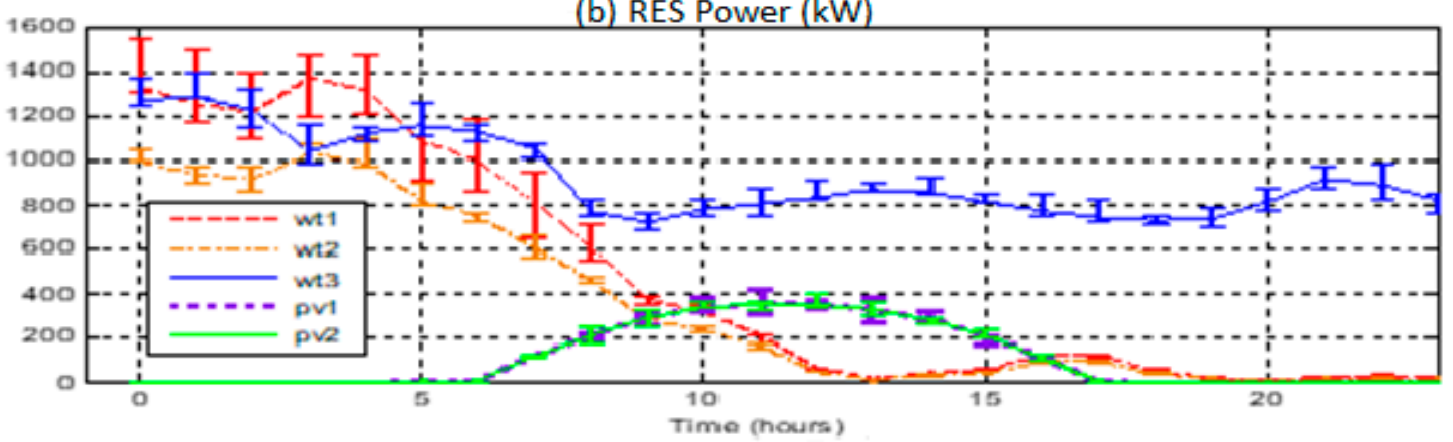

(c) Profit (\$)

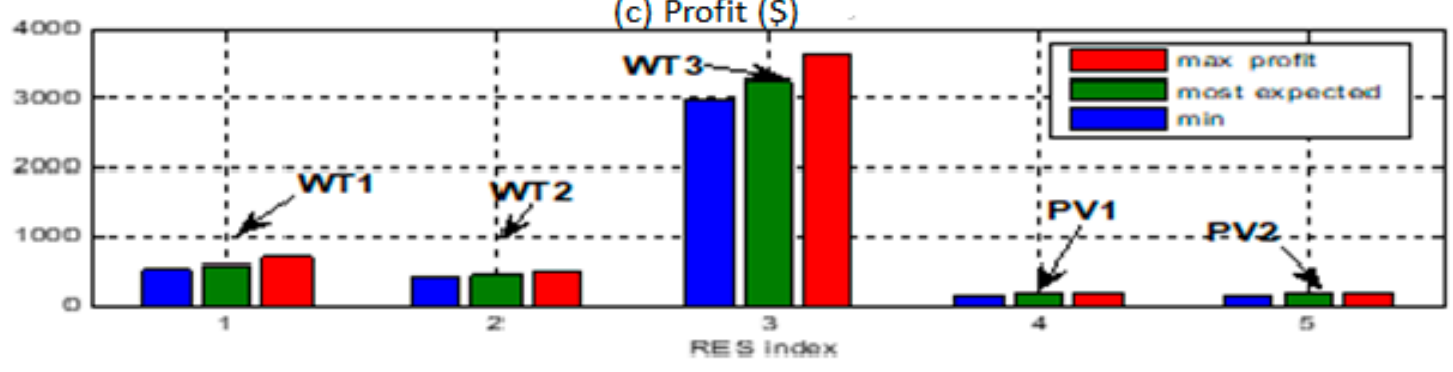

Figure 7. (a) shows the pool price range.(b) depicts RESs' power and its uncertainty. (c) shows the resulting profit of RESs in the case of PT mode trading.

Table 3. DERs rating, Battery Energy Storage System (BESS) storage plans, BESS trading list.

\begin{tabular}{|c|c|c|c|c|c|c|c|}
\hline \multirow{4}{*}{$\begin{array}{c}\text { Ratings } \\
\begin{array}{c}\text { Storage } \\
\text { plans }\end{array}\end{array}$} & \multicolumn{7}{|c|}{$\begin{array}{c}p_{W T 1}=2 M W, p_{W T 2}=1.5 M W, p_{W T 3}=1.5 M W \\
p_{p v 1}=0.5 M W_{,} p_{p v 2}=0.5 M W \\
p_{D S 1}=1 M W / 6 M W h, p_{D S 2_{\text {max }}}=0.5 M W / 2.5 M W h\end{array}$} \\
\hline & Symbol & $s p_{1}$ & $s p_{2}$ & $s p_{3}$ & $s p_{4}$ & $s p_{5}$ & $s p_{6}$ \\
\hline & DNC & 1 & 1 & 1 & 1 & 1 & 2 \\
\hline & DOD & 0.5 & 0.55 & 0.6 & 0.65 & 0.7 & 0.5 \\
\hline \multirow{2}{*}{$\begin{array}{l}\text { RES } \\
\text { agent }\end{array}$} & \multirow{2}{*}{$\begin{array}{l}\text { Bargaining } \\
\text { strategy }\end{array}$} & \multicolumn{2}{|c|}{ Trade history } & \multicolumn{2}{|c|}{ Profitability rank } & \multicolumn{2}{|c|}{ Distance rank } \\
\hline & & DS1 & DS2 & DS1 & DS2 & DS1 & DS2 \\
\hline WT1 & Cool-headed & Med & Med & 3 & 2 & 2 & 2 \\
\hline WT2 & Greedy & Low & Low & 5 & 3 & 1 & 3 \\
\hline WT3 & Anxious & High & High & 1 & 1 & 4 & 5 \\
\hline PV1 & Cool-headed & Med & Low & 4 & 5 & 5 & 1 \\
\hline PV2 & anxious & high & low & 2 & 4 & 3 & 4 \\
\hline
\end{tabular}

To validate the proposed work's effectiveness, four case studies are conducted; two use the distance rank (with and without including the DNO), and the other two use the profitability rank (with and without including the DNO). The MAS frame is evaluated economically by the ESS achieved profit and technically by checking the power flow limit after conducting the trades. Tables $4-7$ show the trade results in the four cases. Table 8 summarizes the storage units' net profit in the four cases. 
Table 4. Trade results in case of distance rank with a distributed network operator (DNO) and energy storage system (ESS) power flow limits.

\begin{tabular}{|c|c|c|c|c|c|c|}
\hline \multirow[t]{2}{*}{ ESS-Agent } & \multirow{2}{*}{$\begin{array}{c}\text { Trading List } \\
\text { Order }\end{array}$} & \multirow{2}{*}{$\begin{array}{c}\text { Best Storage } \\
\text { Plan }\end{array}$} & \multicolumn{3}{|c|}{$\begin{array}{c}\text { Net Profit \$ } \\
\{\text { Min Expected Max }\}\end{array}$} & \multirow{2}{*}{$\begin{array}{c}\left.\text { ESS Profit Share: } \text { pro }_{T S}^{s} \%\right) \\
35.5 \%\end{array}$} \\
\hline & & & $\{\$ 1157.6$ & $\$ 1210.6$ & $\$ 1268.7\}$ & \\
\hline \multirow{4}{*}{$\mathrm{DS}_{1}$} & WT1 & $s p_{1}$ & $\{\$ 507$ & $\$ 538 \$$ & $\$ 567.1\}$ & $39.96 \%$ \\
\hline & PV2 & $s p_{1}$ & $\{\$ 202.8$ & $\$ 218.5$ & $\$ 232.6\}$ & $44.81 \%$ \\
\hline & WT3 & Non & $\{-\$ 89$ & $-\$ 83.4$ & $-\$ 81\}$ & Failure trade \\
\hline & PV2 & Non & $\{-\$ 89$ & $-\$ 83.4$ & $-\$ 81\}$ & Failure trade \\
\hline \multirow{5}{*}{$\mathrm{DS}_{2}$} & PV1 & Non & $\{-\$ 70.9$ & $-\$ 70.7$ & $-\$ 69.9\}$ & Failure trade \\
\hline & WT1 & $s p_{1}$ & $\{\$ 420.7$ & $\$ 462.26$ & $\$ 445.68\}$ & $39.96 \%$ \\
\hline & WT2 & Non & $\{-\$ 103$ & $-\$ 98$ & $-\$ 96.3\}$ & Failure trade \\
\hline & PV2 & Non & $\{-\$ 103$ & $-\$ 98$ & $-\$ 96.3\}$ & Failure trade \\
\hline & WT3 & Non & $\{-\$ 103$ & $-\$ 98$ & $-\$ 96.3\}$ & Failure trade \\
\hline
\end{tabular}

Table 5. Trade results in case of distance rank without a DNO and no ESS power flow limits.

\begin{tabular}{|c|c|c|c|c|c|c|}
\hline \multirow[t]{2}{*}{ ESS-Agent } & \multirow{2}{*}{$\begin{array}{c}\text { Trading List } \\
\text { Order }\end{array}$} & \multirow{2}{*}{$\begin{array}{c}\text { Best Storage } \\
\text { Plan }\end{array}$} & \multicolumn{3}{|c|}{$\begin{array}{c}\text { Net Profit \$ } \\
\{\text { Min Expected Max }\}\end{array}$} & \multirow{2}{*}{$\begin{array}{c}\left.\text { ESS Profit Share: } \operatorname{pro}_{T S}^{s} \%\right) \\
35.5 \%\end{array}$} \\
\hline & & & $\{\$ 1368.6$ & $\$ 1436.3$ & $\$ 1368.6\}$ & \\
\hline \multirow{4}{*}{$\mathrm{DS}_{1}$} & WT1 & $s p_{1}$ & $\{\$ 637.4$ & $\$ 667.3$ & $\$ 693.9\}$ & $39.96 \%$ \\
\hline & PV2 & $s p_{1}$ & $\{\$ 259.8$ & $\$ 280.15$ & $\$ 298.2\}$ & $44.81 \%$ \\
\hline & WT3 & Non & Full ca & pacity is $r$ & reached & Failure trade \\
\hline & PV2 & Non & Full ca & pacity is $r$ & reached & Failure trade \\
\hline \multirow{5}{*}{$\mathrm{DS}_{2}$} & PV1 & Non & $\{-\$ 70.9$ & $-\$ 70.7$ & $-\$ 69.9\}$ & Failure trade \\
\hline & WT1 & $s p_{1}$ & $\{\$ 610.7$ & $\$ 641.3$ & $\$ 664.9\}$ & $39.96 \%$ \\
\hline & WT2 & Non & $\{-\$ 103$ & $-\$ 98$ & $-\$ 96.3\}$ & Failure trade \\
\hline & PV2 & Non & $\{-\$ 103$ & $-\$ 98$ & $-\$ 96.3\}$ & Failure trade \\
\hline & WT3 & Non & $\{-\$ 103$ & $-\$ 98$ & $-\$ 96.3\}$ & Failure trade \\
\hline
\end{tabular}

Table 6. Trade results in case of profitability rank with a DNO and ESS power flow limits.

\begin{tabular}{|c|c|c|c|c|c|c|}
\hline & \multirow{2}{*}{$\begin{array}{c}\text { Trading List } \\
\text { Order }\end{array}$} & \multirow{2}{*}{$\begin{array}{c}\begin{array}{c}\text { Best Storage } \\
\text { Plan }\end{array} \\
s p_{3}\end{array}$} & \multicolumn{3}{|c|}{$\begin{array}{c}\text { Net Profit \$ } \\
\{\text { Min Expected Max }\}\end{array}$} & \multirow{2}{*}{$\begin{array}{c}\left.\text { ESS Profit Share: } \operatorname{pro}_{T S}^{s} \%\right) \\
44.81 \%\end{array}$} \\
\hline & & & $\{\$ 1368.6$ & $\$ 1436.3$ & $\$ 1491.6\}$ & \\
\hline \multirow{4}{*}{$\mathrm{DS}_{1}$} & PV2 & $s p_{1}$ & $\{\$ 371.7$ & $\$ 410.29$ & $\$ 430.50\}$ & $44.81 \%$ \\
\hline & WT1 & $s p_{1}$ & $\{\$ 393.6$ & $\$ 418.14$ & $\$ 436.15\}$ & $39.96 \%$ \\
\hline & WT2 & Non & $\{-\$ 289$ & $-\$ 283.4$ & $-\$ 281\}$ & Failure trade \\
\hline & PV1 & Non & $\{-\$ 289$ & $-\$ 283.4$ & $-\$ 281\}$ & Failure trade \\
\hline \multirow{5}{*}{$\mathrm{DS}_{2}$} & WT3 & Non & $\{-\$ 70.9$ & $-\$ 70.7$ & $-\$ 69.9\}$ & Failure trade \\
\hline & WT1 & $s p_{1}$ & $\{\$ 420.7$ & $\$ 462.26$ & $\$ 445.68\}$ & $44.81 \%$ \\
\hline & WT2 & Non & $\{-\$ 103$ & $-\$ 98$ & $-\$ 96.3\}$ & Failure trade \\
\hline & PV2 & Non & $\{-\$ 103$ & $-\$ 98$ & $-\$ 96.3\}$ & Failure trade \\
\hline & PV1 & Non & $\{-\$ 103$ & $-\$ 98$ & $-\$ 96.3\}$ & Failure trade \\
\hline
\end{tabular}


Table 7. Trade results in case of profitability rank without a DNO and no ESS power flow limits.

\begin{tabular}{|c|c|c|c|c|c|c|}
\hline \multirow[t]{2}{*}{ ESS-Agent } & \multirow{2}{*}{$\begin{array}{c}\text { Trading List } \\
\text { Order } \\
\text { WT3 }\end{array}$} & \multirow{2}{*}{$\begin{array}{c}\text { Best Storage } \\
\text { Plan } \\
s p_{3}\end{array}$} & \multicolumn{3}{|c|}{$\begin{array}{c}\text { Net Profit \$ } \\
\{\text { Min Expected Max }\}\end{array}$} & \multirow{2}{*}{$\begin{array}{c}\left.\text { ESS Profit Share: } \text { pro }_{T S}^{s} \%\right) \\
44.81 \%\end{array}$} \\
\hline & & & $\{\$ 1368.6$ & $\$ 1436.3$ & $\$ 1491.6\}$ & \\
\hline \multirow{4}{*}{$\mathrm{DS}_{1}$} & PV2 & $s p_{1}$ & $\{\$ 496.8$ & $\$ 530.89$ & $\$ 560.62\}$ & $44.81 \%$ \\
\hline & WT1 & $s p_{1}$ & $\{\$ 393.6$ & $\$ 418.14$ & $\$ 436.15\}$ & $39.96 \%$ \\
\hline & WT2 & Non & \multirow{2}{*}{\multicolumn{3}{|c|}{$\begin{array}{l}\text { Full capacity is reached } \\
\text { Full capacity is reached }\end{array}$}} & Failure trade \\
\hline & PV1 & Non & & & & Failure trade \\
\hline \multirow{5}{*}{$\mathrm{DS}_{2}$} & WT3 & Non & $\{-\$ 70.9$ & $-\$ 70.7$ & $-\$ 69.9\}$ & Failure trade \\
\hline & WT1 & $s p_{1}$ & $\{\$ 610.7$ & $\$ 641.3$ & $\$ 664.9\}$ & $44.81 \%$ \\
\hline & WT2 & Non & $\{-\$ 103$ & $-\$ 98$ & $-\$ 96.3\}$ & Failure trade \\
\hline & PV2 & Non & $\{-\$ 103$ & $-\$ 98$ & $-\$ 96.3\}$ & Failure trade \\
\hline & PV1 & Non & $\{-\$ 103$ & $-\$ 98$ & $-\$ 96.3\}$ & Failure trade \\
\hline
\end{tabular}

Table 8. Storage units' total profit with different strategies.

\begin{tabular}{ccc}
\hline Trading Strategy & $D S_{1}$ Total Profit (\$) & $D_{2}$ Total Profit (\$) \\
\hline $\begin{array}{c}\text { Distance rank-with DNO and } \\
\text { ESS power limits }\end{array}$ & $\$ 742.65$ & $\$ 184.72$ \\
$\begin{array}{c}\text { Distance rank-without DNO and } \\
\text { no ESS power limits }\end{array}$ & $\$ 902$ & $\$ 256.14$ \\
$\begin{array}{c}\text { Profitability rank-with DNO and } \\
\text { ESS power limits }\end{array}$ & $\$ 994.54$ & $\$ 207.138$ \\
$\begin{array}{c}\text { Profitability rank-without DNO } \\
\text { and no ESS power limits }\end{array}$ & $\$ 1048.58$ & $\$ 287.36$ \\
\hline
\end{tabular}

We assume that the desired BESS-profit in TS-Mode is $50 \%$ of the profit share given it is greater than the profit with the grid (EA-Mode). In such a case, the BESS ask price is calculated as $p r o_{T S}^{s}=\max \left(0.5\left(p r o_{T S}^{s r}-p r o_{P T}^{r}\right), p r o_{E A}^{s}\right)$. On the other hand, we assume that the mentality of all RESs is given $30 \%$ of the profit to the ESS-agent; $\beta=0.7\left(\right.$ pro $\left._{T S}^{s r}-p r o_{P T}^{r}\right)$. As a result, BESS- and RES-agents will always bargain according to each agent attitude until the final BESS profit share is reached.

As in Table 3, all the BESS-agents act as cool-headed, while the mentality of RES-agents has different risk levels. Due to market price, RES uncertainty, the net profit is defined by a minimum, maximum, and most expected values. During the trade, all RES- and ESS-agents have adopted the most expected value in the calculation.

In the case of distance rank (Tables 4 and 5), DS1 starts with the nearest RES-agent WT2. As WT2 acts as a greedy, DS1 only manages to get a $35.5 \%$ share of the net profit. The most profitable plan for DS1 is Sp3, since the other plans will lead to less TS-Mode profit. The second RES in the distance rank is WT1, which represents a cool-headed agent. Thus, DS1 manages to get higher profit than WT2; however, the net profit for WT1 is less than WT2, although there wind generation is not so different; This is because WT2 has a higher rank in the trading list than WT1; so it managed to sell its energy in the highest peak-hours. The third RES-agent is PV2, which acts as an anxious agent, and the BESS has managed to get a $44.81 \%$ profit share. It should be noticed that without DNO, no power flow constraints are imposed on the BESSs; therefore, the trade revenue increases but a power flow limit violation may occur. After the third deal, the BESS capacity has reached its 6 MWh limit (in case of No $\mathrm{DNO}$ ) or has a low capacity in case of using DNO, and the profit becomes negative, and no more deals are conducted.

In the case of distance rank, regarding DS2, it represents a parking lot with charging hours between (2:7 am) according to the charging strategy proposed in [39]. Thus, trading with PV in TS-Mode was not successful (negative profit). As a result, DS2 has moved to the next RES in his list, which is WT1 to 
achieve a successful trade since WT1 generates its power after midnight. Although DS2 has not reached its full capacity, WT1 has occupied all its charging hours leading to a following unsuccessful trades.

For the profitability trade (Tables 6 and 7), the generous RES-agents occupied a higher rank in the trading list, selling their energy during the most attractive peak hours and achieving a higher net profit margin. As these generous agents share a high-profit margin with the BESS-agents, the BESS gains higher profit than the distance rank as highlighted in Table 8. The agent DS1 has achieved $\$ 994.54$ with profitability rank instead of $\$ 742.65$ with a distance rank representing a $33.3 \%$ increase in profit. The agent DS2 has achieved $\$ 207.138$ with profitability rank instead of $\$ 184.7$ with a distance rank representing a $12.14 \%$ increase in profit.

Figure 8 shows the effect of the trades on the power flow in case of adopting the distance rank (Figure $8 \mathrm{a}-\mathrm{f}$ ) and profitability rank (Figure $8 \mathrm{~g}-\mathrm{m}$ ). It is noticed that the battery charging limits and capacity limits (SOC) are acceptable due to the post-auction phase. For the BESS power flow charging limits, as shown in Figure 8c,e,h,l, without considering the DNO, the power flow limits are violated during trading (highlighted by circles), leading to the under-voltage occurrence as shown in Figure 9, which depicts the voltage profile in case of profitability rank with and without DNO. Voltage violations (under-voltage less than 0.95) have occurred from (11 am: $1 \mathrm{pm}$ ), which align with the BESS power flow charging limits violation in Figure $8 \mathrm{~h}$. On the other hand, when the DNO-agent is considered, the voltage profit stays within limits.

To sum up, from an economic perspective, the proposed profitability rank has achieved a higher profit than the distance rank for the ESS-agents. The profit-sharing between the agents is related to their auctioning strategy and eagerness for this trade. Adopting a DNO adds more limits to the BESS power leading to some profit reduction, which is a necessary price paid to guarantee power quality and reliability. In terms of the long-term techno-economic impacts, the following behaviors are expected after adopting many trades:

- ESS-agents will develop a mature and well-investigated trading list. Each ESS-agent may even have favorable RES trading partners.

- With the increasing number of ESS- and RES-agents, the computation time of the MAS algorithm will be longer. The solution to this problem is either by increasing the negotiations window time or improving the computers' processing power.

- Some ESS-agents can have longer than one day-ahead contract with RES-agents. It will be interesting to have a weekly or monthly collaboration. The problem that faces long time trading is the uncertainty of the market price and RES power.

The optimization problems (1) and (17) have been solved using YALMIP [40] and MATLAB linear programming solver with a $3.50 \mathrm{GHz}$ Intel-i5 processor. The processing time is summarized as follows:

- During the pre-auction phase, the DNO solves a power flow problem. The communication delay is the network delay and the solver time for the power flow problem, which is around $4.166 \mathrm{~s}$.

- During the auction phase, for a specific plan (TS- or ES-Modes), the linear programming solver time is around $0.7-0.9 \mathrm{~s}$ per trade.

- During the post-auction phase, updating the BESSs power limits takes around $0.076 \mathrm{~s}$ for this system.

Given the processing time, assuming the negotiation window is one hour or several minutes, an ESS-agent has sufficient time to complete various negotiations with many RES-agents. Multi-second communication delay would not introduce an issue for this day-ahead trading model. The DNO can impose a time limit for the auctioning phase to avoid such a problem. 
(a) DS1 \& WT2

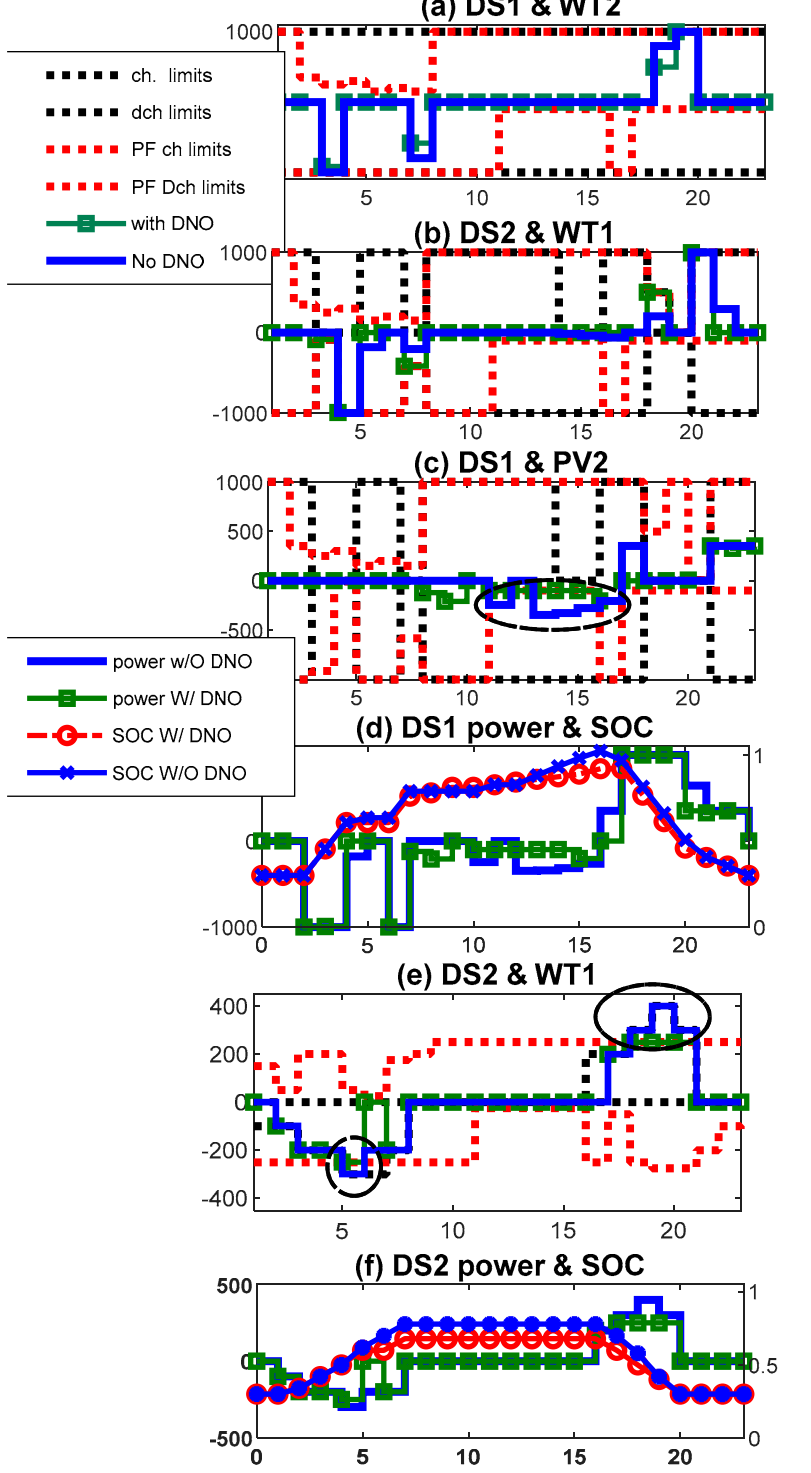

(g) DS1\& WT3

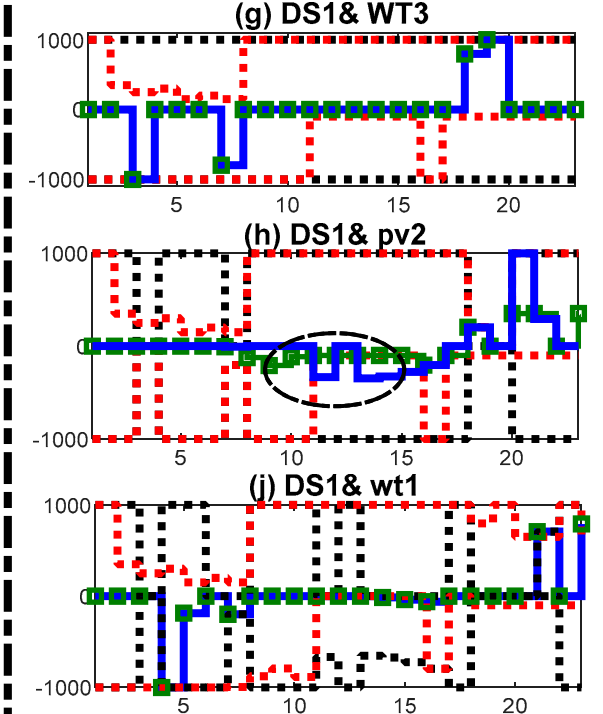

(k) DS1 power \& SOC

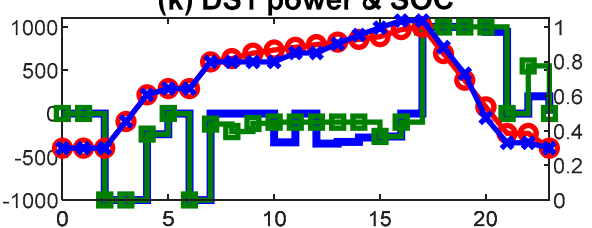

(I) DS2\& WT3

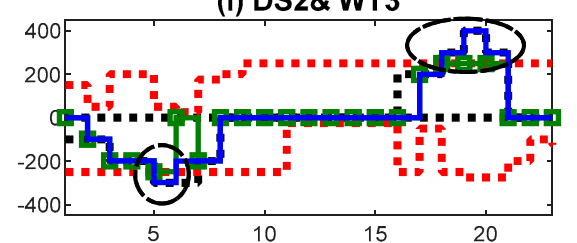

(m) DS2 power \& SOC

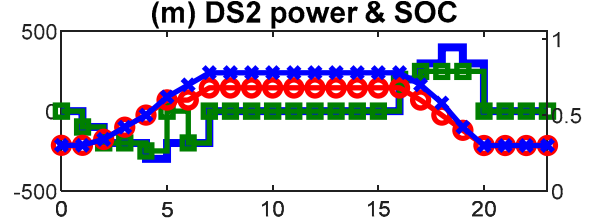

Figure 8. Simulation results for all agents' trades. Figure 8a-f show the storage power and SOC with and without a DNO in case of a distance rank trading. Figure $8 \mathrm{~g}-\mathrm{m}$ show the storage power and SOC with and without a DNO in case of a profitability rank trading. 
(a) Voltage profile with DNO

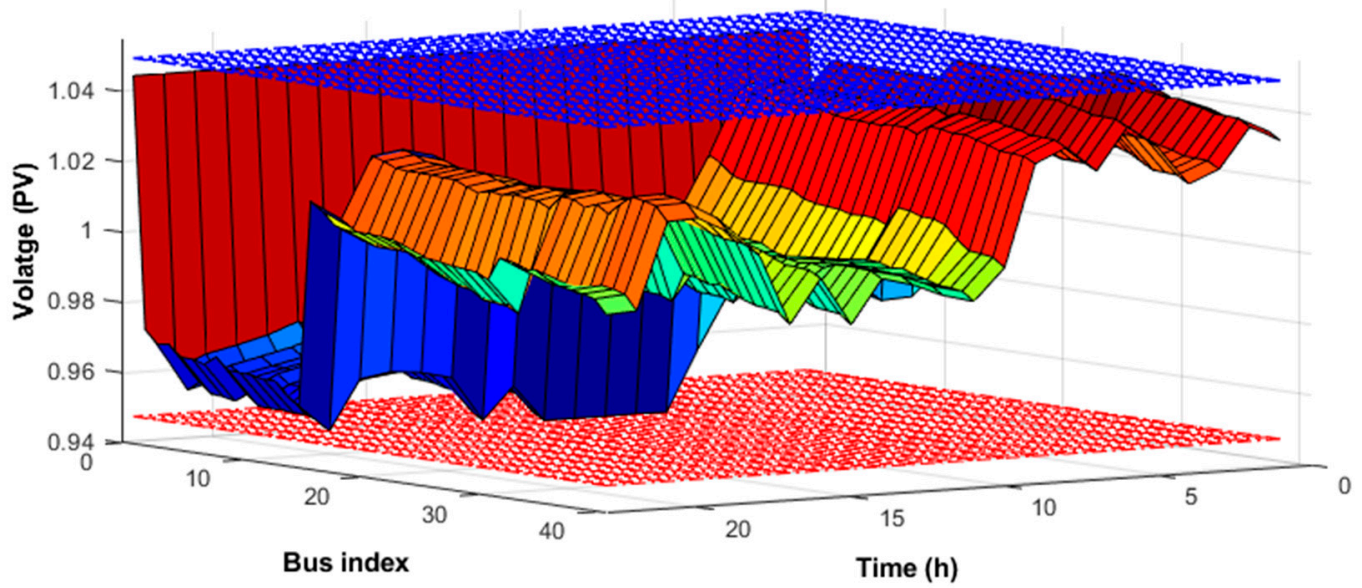

(b) voltage profile without DNO

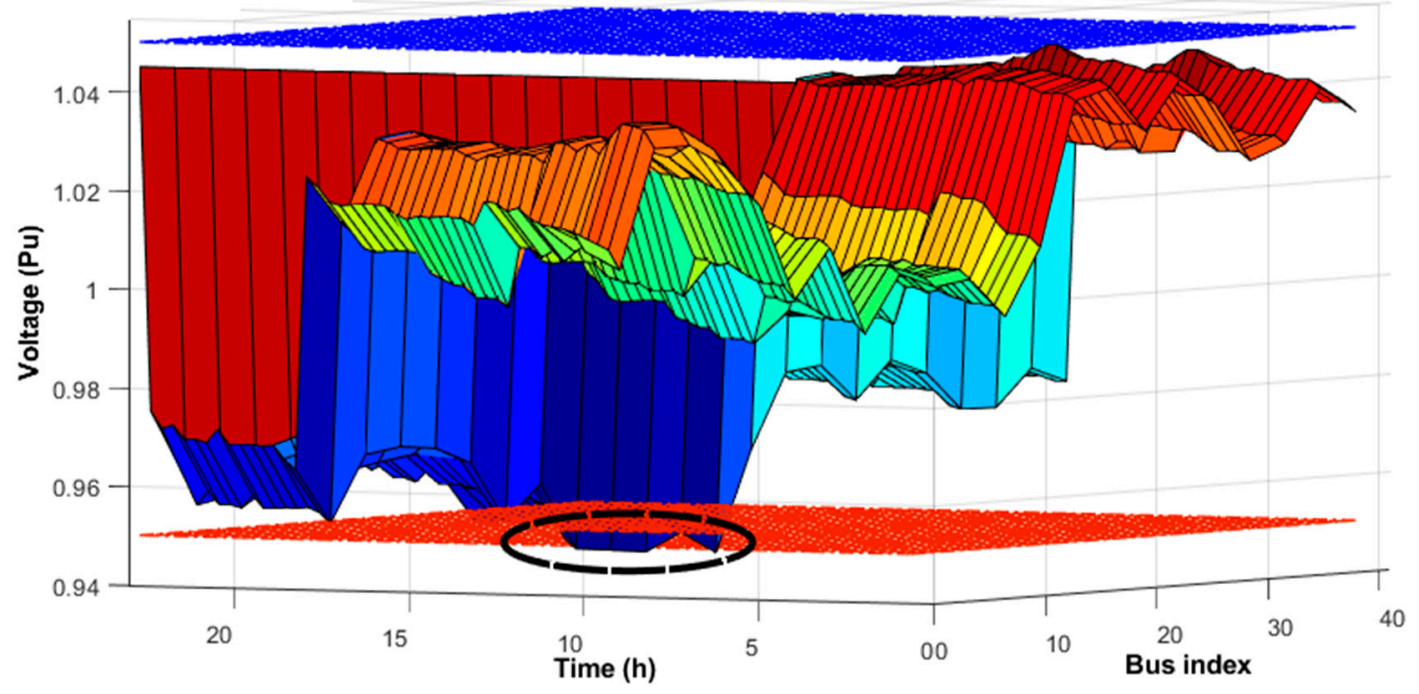

Figure 9. Voltage surface for the incoming day with $\mathrm{DNO}(\mathbf{a})$ and without considering the DNO (b).

\section{Conclusions}

This work presents a multiagent framework for collaboration between BESSs and RESs owned by different owners. The owners have different trading strategies and risk levels. The RES-agents can trade with the grid directly (Price Taker Mode) or a BESS-agent (Energy Time-Shifting Mode). The ESS-agent can trade with the grid (Energy-Arbitrage Mode), or an RES-agent. The framework represents a decentralized auctioning strategy between the grid, ESS-, and RES-agents. The agents can pick between the different three modes (price taker, time-shifting, or energy arbitrage) to maximize their profit. The market and RES energy uncertainty are modeled by min, average, and max values. The DNO agent guarantees a proper power system flow. The RES- and ESS-agents learn from previous trades using a proposed ANFIS learning expert. The expert aims at maximizing the agent profit while considering the system uncertainties. The trading is conducted through three phases (pre-auction, auction, and post-auction).

A case study on a real distribution feeder has been conducted to validate this work. The case study compared the proposed MAS framework with a distance-based MAS. The simulation results show that the proposed MAS provided higher profits to the owners and accommodates different risk levels. The proposed MAS framework enables the DNO to keep a safe power system operation. The DNO does not intervene in the owners' trading strategy or profit. The MAS framework has the advantages 
of being robust, distributed, and scalable since adding more or removing BESS- or RES-agents is conducted without affecting the system operation.

Author Contributions: Conceptualization, H.M.A. and Y.A.I.M.; Methodology, H.M.A.; Software, H.M.A.; Validation, H.M.A., Formal Analysis, H.M.A.; Investigation, H.M.A.; Resources, H.M.A., Y.A.I.M.; Data Curation, H.M.A.; Writing-Original Draft Preparation, H.M.A.; Writing—Review \& Editing, H.M.A., Y.A.I.M.; Visualization, H.M.A.; Supervision, Y.A.I.M.; Project Administration, Y.A.I.M.; Funding Acquisition, Y.A.I.M. All authors have read and agreed the published version of the manuscript.

Funding: This work was supported in part by the National Sciences and Engineering Research Council of Canada, and in part by the Future Energy Systems Research through the Canada First Research Excellence Fund (CFREF).

Conflicts of Interest: The authors declare no conflict of interest.

\section{Nomenclature}

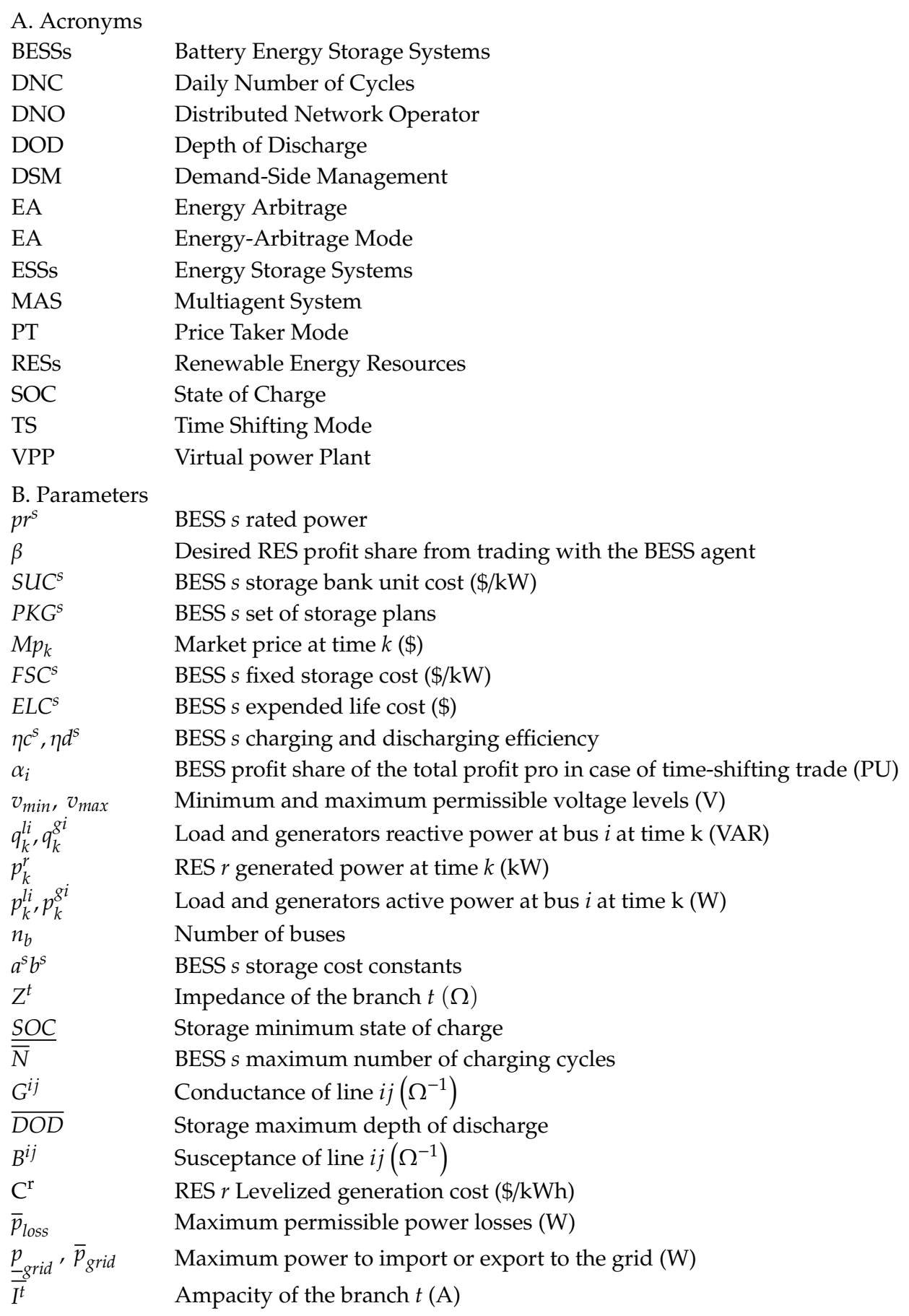




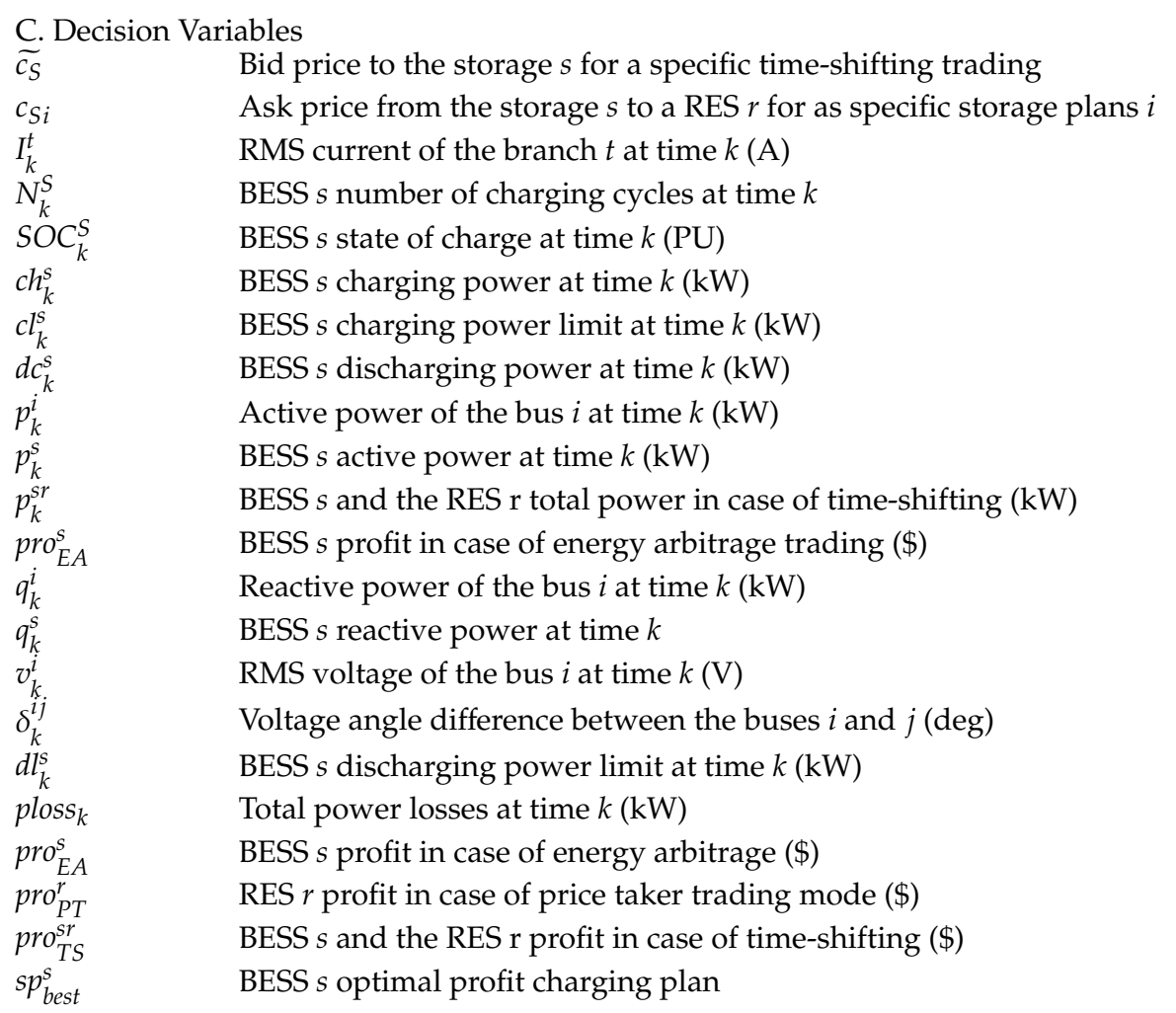

\section{References}

1. McArthur, S.D.J.; Davidson, E.M.; Catterson, V.M.; Dimeas, A.L.; Hatziargyriou, N.D.; Ponci, F.; Funabashi, T. Multi-Agent Systems for Power Engineering Applications-Part I: Concepts, Approaches, and Technical Challenges. IEEE Trans. Power Syst. 2007, 22, 1743-1752. [CrossRef]

2. Nguyen, D.H.; Khazaei, N. Multiagent Time-Delayed Fast Consensus Design for Distributed Battery Energy Storage Systems. IEEE Trans. Sustain. Energy 2019, 9, 1397-1406. [CrossRef]

3. Liu, J.; He, D.; Wei, Q.; Yan, S. Energy Storage Coordination in Energy Internet Based on Multi-Agent Particle Swarm Optimization. Appl. Sci. 2018, 8, 1520. [CrossRef]

4. Xu, D.; Zhang, W.; Jiang, B.; Shi, P.; Wang, S. Directed-Graph-Observer-Based Model-Free Cooperative Sliding Mode Control for Distributed Energy Storage Systems in DC Microgrid. IEEE Trans. Ind. Inform. 2019, 16, 1224-1235. [CrossRef]

5. Bui, V.-H.; Hussain, A.; Kim, H.-M. A Multiagent-Based Hierarchical Energy Management Strategy for Multi-Microgrids Considering Adjustable Power and Demand Response. IEEE Trans. Smart Grid 2016, 9, 1323-1333. [CrossRef]

6. Harmouch, F.Z.; Krami, N.; Hmina, N. A multiagent based decentralized energy management system for power exchange minimization in microgrid cluster. Sustain. Cities Soc. 2018, 40, 416-427. [CrossRef]

7. Li, C.; Coelho, E.A.A.; Dragicevic, T.; Guerrero, J.M.; Vasquez, J.C. Multiagent-Based Distributed State of Charge Balancing Control for Distributed Energy Storage Units in AC Microgrids. IEEE Trans. Ind. Appl. 2016, 53, 2369-2381. [CrossRef]

8. Chen, F.; Chen, M.; Li, Q.; Meng, K.; Guerrero, J.M.; Abbott, D. Multiagent-Based Reactive Power Sharing and Control Model for Islanded Microgrids. IEEE Trans. Sustain. Energy 2016, 7, 1232-1244. [CrossRef]

9. Ghazvini, M.A.F.; Abedini, R.; Pinto, T.; Vale, Z. Multiagent System Architecture for Short-term Operation of Integrated Microgrids. IFAC Proc. Vol. 2014, 47, 6355-6360. [CrossRef]

10. Zhao, T.; Ding, Z. Cooperative Optimal Control of Battery Energy Storage System Under Wind Uncertainties in a Microgrid. IEEE Trans. Power Syst. 2017, 33, 2292-2300. [CrossRef]

11. Prabawa, P.; Choi, D.-H. Multi-Agent Framework for Service Restoration in Distribution Systems With Distributed Generators and Static/Mobile Energy Storage Systems. IEEE Access 2020, 8, 51736-51752. [CrossRef]

12. Yang, L.; Xu, Y.; Sun, H.; Chow, M.; Zhou, J. A multiagent system based optimal load restoration strategy in distribution systems. Int. J. Electr. Power Energy Syst. 2021, 124, 106314. [CrossRef] 
13. Martin, R.; Christian, L.; Roland, Z.; Andreas, R.; Andrea, H.; Gunther, R. Smart Grid for Industry Using Multi-Agent Reinforcement Learning. Appl. Sci. 2020, 10, 6900.

14. Morais, H.; Pinto, T.; Vale, Z.; Praça, I. Multilevel Negotiation in Smart Grids for VPP Management of Distributed Resources. IEEE Intell. Syst. 2012, 27, 8-16. [CrossRef]

15. Amin, M.; Ballard, D. Defining new markets for intelligent agents. IT Prof. 2000, 2, 29-35. [CrossRef]

16. Ramachandran, B.; Srivastava, S.K.; Edrington, C.S.; Cartes, D.A. An Intelligent Auction Scheme for Smart Grid Market Using a Hybrid Immune Algorithm. IEEE Trans. Ind. Electron. 2010, 58, 4603-4612. [CrossRef]

17. Nunna, H.S.V.S.K.; Doolla, S. Energy Management in Microgrids Using Demand Response and Distributed Storage-A Multiagent Approach. IEEE Trans. Power Deliv. 2013, 28, 939-947. [CrossRef]

18. Dimeas, A.; Hatziargyriou, N. Operation of a Multiagent System for Microgrid Control. IEEE Trans. Power Syst. 2005, 20, 1447-1455. [CrossRef]

19. Nunna, H.S.V.S.K.; Doolla, S. Multiagent-Based Distributed-Energy-Resource Management for Intelligent Microgrids. IEEE Trans. Ind. Electron. 2012, 60, 1678-1687. [CrossRef]

20. Kahrobaee, S.; Rajabzadeh, R.A.; Soh, L.-K.; Asgarpoor, S. A Multiagent Modeling and Investigation of Smart Homes With Power Generation, Storage, and Trading Features. IEEE Trans. Smart Grid 2012, 4, 659-668. [CrossRef]

21. Logenthiran, T.; Srinivasan, D.; Khambadkone, A.M.; Aung, H.N. Multiagent System for Real-Time Operation of a Microgrid in Real-Time Digital Simulator. IEEE Trans. Smart Grid 2012, 3, 925-933. [CrossRef]

22. Colson, C.M.; Nehrir, M.H.; Sharma, R.K.; Asghari, B. Improving Sustainability of Hybrid Energy Systems Part I: Incorporating Battery Round-Trip Efficiency and Operational Cost Factors. IEEE Trans. Sustain. Energy 2013, 5, 37-45. [CrossRef]

23. Colson, C.M.; Nehrir, M.H.; Sharma, R.K.; Asghari, B. Improving Sustainability of Hybrid Energy Systems Part II: Managing Multiple Objectives With a Multiagent System. IEEE Trans. Sustain. Energy 2013, 5, 46-54. [CrossRef]

24. Wu, T.; Xia, Y.; Wang, L.; Wei, W. Multiagent Based Distributed Control with Time-Oriented soc Balancing Method for DC Microgrid. Energies 2020, 13, 2793. [CrossRef]

25. Nunna, H.S.V.S.K.; Sesetti, A.; Rathore, A.K.; Doolla, S. Multiagent-Based Energy Trading Platform for Energy Storage Systems in Distribution Systems With Interconnected Microgrids. IEEE Trans. Ind. Appl. 2020, 56, 3207-3217. [CrossRef]

26. Jiang, W.; Yang, K.; Yang, J.; Mao, R.; Xue, N.; Zhuo, Z. A Multiagent-Based Hierarchical Energy Management Strategy for Maximization of Renewable Energy Consumption in Interconnected Multi-Microgrids. IEEE Access 2019, 7, 169931-169945. [CrossRef]

27. Piwko, R.; Osborn, D.; Gramlich, R.; Jordan, G.; Hawkins, D.; Porter, K. Wind energy delivery issues [transmission planning and competitive electricity market operation. IEEE Power Energy Mag. 2005, 3, 47-56. [CrossRef]

28. Poonpun, P.; Jewell, W.T. Analysis of the Cost per Kilowatt Hour to Store Electricity. IEEE Trans. Energy Convers. 2008, 23, 529-534. [CrossRef]

29. Zhou, C.; Qian, K.; Allan, M.; Zhou, W. Modeling of the Cost of EV Battery Wear Due to V2G Application in Power Systems. IEEE Trans. Energy Convers. 2011, 26, 1041-1050. [CrossRef]

30. Abdeltawab, H.H.; Mohamed, Y.A.-R.I.; Ibrahim, Y. Market-Oriented Energy Management of a Hybrid Wind-Battery Energy Storage System Via Model Predictive Control with Constraint Optimizer. IEEE Trans. Ind. Electron. 2015, 62, 6658-6670. [CrossRef]

31. Perez, E.; Beltran, H.; Aparicio, N.; Rodriguez, P. Predictive Power Control for PV Plants with Energy Storage. IEEE Trans. Sustain. Energy 2012, 4, 482-490. [CrossRef]

32. Eyer, J.; Corey, G. Energy Storage for the Electricity Grid: Benefits and Market Potential Assessment Guide; Sandia National Laboratories: Albuquerque, NM, USA, 2010.

33. Pedrycz, W.; Gomide, F. Fuzzy Systems Engineering Toward Human-Centric Computing; Wiley: Hoboken, NJ, USA, 2007.

34. Jang, J.-S.R. ANFIS: Adaptive-network-based fuzzy inference system. IEEE Trans. Syst. Man Cybern. 1993, 23, 665-685. [CrossRef]

35. Wang, Z.; Wang, L. Adaptive Negotiation Agent for Facilitating Bi-Directional Energy Trading Between Smart Building and Utility Grid. IEEE Trans. Smart Grid 2013, 4, 702-710. [CrossRef] 
36. Atwa, Y.M. Distribution System Planning and Reliability Assessment under High DG Penetration. Ph.D. Thesis, University of Waterloo, Waterloo, ON, Canada, 2010.

37. Lopez, E.; Opazo, H.; Garcia, L.; Bastard, P. Online Reconfiguration Considering Variability Demand: Applications to Real Networks. IEEE Trans. Power Syst. 2004, 19, 549-553. [CrossRef]

38. AESO. Historical Pool Price for Alberta. 2000. Available online: http://ets.aeso.ca/ (accessed on 15 September 2020).

39. Xu, D.Q.; Joós, G.; Levesque, M.; Maier, M. Integrated V2G, G2V, and Renewable Energy Sources Coordination Over a Converged Fiber-Wireless Broadband Access Network. IEEE Trans. Smart Grid 2013, 4, 1381-1390.

40. Löfberg, J. YALMIP. Available online: https://yalmip.github.io/ (accessed on 6 October 2020).

Publisher's Note: MDPI stays neutral with regard to jurisdictional claims in published maps and institutional affiliations.

(C) 2020 by the authors. Licensee MDPI, Basel, Switzerland. This article is an open access article distributed under the terms and conditions of the Creative Commons Attribution (CC BY) license (http://creativecommons.org/licenses/by/4.0/). 